\title{
Time Delay Effect on Regenerative Chatter in Tandem Rolling Mills
}

\author{
Xiaochan Liu, Yong Zang, Zhiying Gao, and Lingqiang Zeng \\ School of Mechanical Engineering, University of Science and Technology Beijing, Beijing 100083, China \\ Correspondence should be addressed to Yong Zang; yzang@ustb.edu.cn
}

Received 1 September 2015; Revised 8 December 2015; Accepted 17 December 2015

Academic Editor: Kumar V. Singh

Copyright ( 2016 Xiaochan Liu et al. This is an open access article distributed under the Creative Commons Attribution License, which permits unrestricted use, distribution, and reproduction in any medium, provided the original work is properly cited.

\begin{abstract}
The interstand tension coupling effect and strip gauge variation passed on to next stand with time delay are the main causes for regenerative chatter in tandem rolling mills. To study the effect of different factors on the stability of tandem rolling mills, different models considering different interstand factors were built. Through stability analysis of these models by employing the Lyapunov indirect method and integral criterion, more detailed and quantitative explanation is put forward to regenerative chatter mechanism in rolling. To study the time delay effect as a single factor on the stability of tandem rolling mills, stability charts of the chatter model including the time delay effect and model neglecting the delay time were compared. The results show that the time delay effect reduces the critical velocity of multistand mills slightly in the big picture. But it alters the relationship between two adjacent stands by worsening the downstream stand stability. To get preferable rolling process parameter configuration for the tandem rolling mills, the time delay effect in rolling must be involved.
\end{abstract}

\section{Introduction}

Chatter in high speed rolling mills results in unacceptable gauge variations, affects the surface quality of rolled strip, and may damage the mill stand. Many studies have been conducted to explore the chatter mechanism and put forward methods to suppress the vibration [1]. The self-excited vibration in rolling is caused by interaction between mill stand structure and rolling process. Rolling chatter has three main different types: third octave, fifth octave, and torsional vibration. The third octave is the most detrimental $[2,3]$. The chatter mechanism in tandem rolling mills can be concluded as four reasons, namely, model matching effect, negative damping effect, mode coupling effect, and regenerative effect. Regenerative effect is the most complex mechanism for instability in tandem rolling mills $[4,5]$.

Regenerative effect in rolling mainly considers the interaction between adjacent stands in tandem rolling mills. $\mathrm{Hu}$ first defined the regenerative chatter in rolling process in analogy to chatter in metal cutting process. According to Hu's definition, the regenerative effect in strip rolling refers to the phenomenon that the vibration of a certain stand at a prior time causes or aggravates vibration of the same stand at the current time through interstand interactions [6]. By building a dynamic rolling process model and coupling it with stand structure model, a multistand regenerative chatter model was proposed. Simulation and analysis were conducted to reveal the regenerative mechanism. The results have shown that, due to the needed time for the strip to travel from one stand to another, a tandem mill can become unstable even if individual mill stands are stable [5].

Considering the work hardening effect of the rolled piece and work roll flattening during rolling process, a new rolling process model was proposed by Zhao and Ehmann. Through coupling it with mill stand model, three different models were built to explore the regenerative mechanism. The first one is a single stand chatter model. The second one is a two-stand chatter model which only considers the interstand tension coupling effect [7]. The last one is a two-stand chatter model which considers both the interstand tension coupling effect and the strip gauge variation from an upstream stand passed on to downstream stand with time delay. The Routh criterion was employed to formulate the critical velocity of the first and second model. Due to the time delay effect, the third model 
becomes a delay differential system and integral criterion was employed to find its critical velocity. Comparative analysis of the three models presented a potential explanation to the regenerative mechanism [4].

Based on Zhao and Ehmann's and Hu's model, more complex regenerative chatter models are proposed in recent years. Kimura et al. constructed a five-stand regenerative chatter model by coupling a five-degree freedom mill stand model and the dynamic rolling model built in [7] together. The simulation results show that there exists an optimal friction of the fifth stand which relates to the maximum critical velocity of the whole tandem rolling mills [8]. Instead of static analysis, Niroomand et al. used wave propagation theory in elastic solids to formulate the dynamic tensile stress variation between two consequent stands and built a new two-stand regenerative chatter model. The simulation results show that the errors of critical velocity and chatter frequency are smaller with the experimental results, when the wave propagation theory is applied [9]. Considering the complex friction condition in the rolling gap, Heidari et al. built a regenerative chatter model using the unsteady lubrication model, assuming that the rolling gap is in full film regime. The effects of rolling lubricant on the stability of tandem rolling mills were discussed [10]. Based on these regenerative chatter models, optimization of multistand rolling process parameters were conducted to avoid chatter phenomenon using the combination of neural networks and genetic algorithms [11, 12].

All these regenerative chatter models have considered the time delay effect, which makes the tandem rolling mills a delay differential system. It means that more complex stability criterion has to be employed to analyze the delay differential multistand system, which results in huge computation. However, the time delay effect on the stability of tandem rolling mills has not been analyzed as an independent factor. More research work has to be done to decide whether the effect of time delay itself on the stability of tandem rolling mills is worth the great amount of computation. Besides, the relationship between consequent stands is not clearly described though the interaction factors between stands have been pointed out. The major objective pursed in this paper is to investigate the time delay effect as an independent factor in cold rolling tandem mills and put forward more detailed explanation to the regenerative chatter mechanism and the relations between consecutive stands.

\section{Chatter Model}

The dynamic rolling gap is shown as in Figure 1, when only the vertical roll vibration is considered. Set the coordinates $x$ and $y$ onto the center line of rolled piece and the work roll center line. And the intersection point is set as the origin of coordinates. $\sigma_{e}$ and $\sigma_{d}$ are the entry and exit tensile stress. $v_{e}$ and $v_{d}$ are the entry and exit strip velocity. $h_{e}$ and $h_{d}$ are the strip thickness at entry and exit. $v_{r}$ is the work roll linear velocity. $h_{n}$ is the strip thickness at neutral point. $x_{e}, x_{n}$, and $x_{d}$ are the position of entry point, neutral point, and exit point.

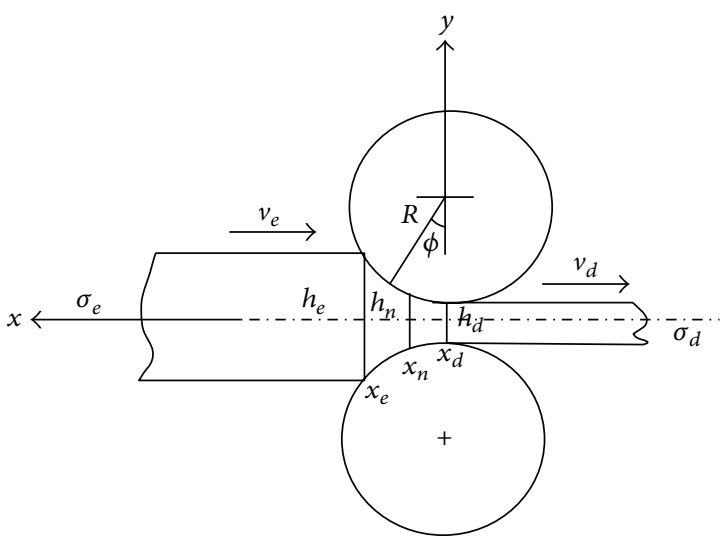

FIGURE 1: Dynamic rolling gap.

The strip thickness at any $x$ location in the rolling gap is as follows:

$$
h=h_{d}+\frac{x^{2}}{R} .
$$

Due to the roll vertical vibration, the continuity equation is modified as

$$
v h=v_{e} h_{e}+\left(x-x_{e}\right) \dot{h}_{d} .
$$

According to (1) and (2), the strip entry velocity $v_{e}$, strip exit velocity $v_{d}$, strip entry position $x_{e}$, and exit position $x_{d}$ can be calculated as follows:

$$
\begin{aligned}
& v_{e}=\frac{1}{h_{e}}\left(v_{r} h_{d}+\frac{v_{r} x_{n}^{2}}{R}+\left(x_{e}-x_{n}\right) \dot{h}_{d}\right), \\
& v_{d}=\frac{v_{e} h_{e}+\left(x_{d}-x_{e}\right) \dot{h}_{d}}{h_{d}+x_{d}^{2} / R}, \\
& x_{e}=\sqrt{R\left(h_{e}-h_{d}\right)} \\
& x_{d}=\frac{R h_{d} \dot{h}_{d}}{2\left(v_{e} h_{e}-x_{e} \dot{h}_{d}\right)} .
\end{aligned}
$$

Figure 2 illustrates the stresses acting on a vertical slab element inside the rolling gap. Employing the coulomb friction model $\tau_{s}=\mu p$ and the yield criterion $\sigma_{x}=k_{f}-p$, the equilibrium equation for an elemental vertical section of the strip in the rolling gap in the $x$ direction is obtained:

$$
\frac{d p}{d x} \mp \frac{2 \mu p}{h}-\frac{1}{h} \frac{d\left(h k_{f}\right)}{d x}=0,
$$

where the positive sign is for the exit side and the negative sign is for the entry side.

Considering the strain hardening effect, the deformation resistance of the rolled strip can be expressed as follows:

$$
k_{f}=\sigma_{0}\left(A+\ln \left(\frac{h_{0}}{h}\right)\right)^{n} .
$$




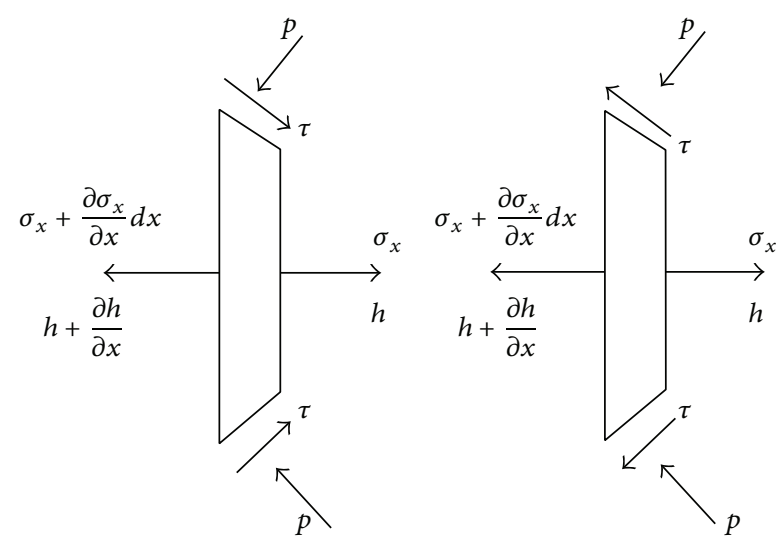

FIGURE 2: Slab analysis on a volume element of the entry region and exit region.

$\sigma_{0}, A$, and $n$ are the material property parameter of the rolled strip and can be decided by experiments. $h_{0}$ is the entry strip thickness of multistand rolling mills.

Applying the boundary conditions,

$$
\begin{aligned}
& \left.p\right|_{x=x_{e}}=k_{f e}-\sigma_{e}, \\
& \left.p\right|_{x=x_{d}}=k_{f d}-\sigma_{d} .
\end{aligned}
$$

The rolling pressure at entry and exit side can be obtained:

$$
\begin{aligned}
p_{e} & =\left(k_{f e}-\sigma_{e}\right) \frac{h k_{f}}{h_{e} k_{f e}} \exp \left(u \left(2 \sqrt{\frac{R}{h_{d}}} \tan ^{-1}\left(\frac{x_{e}}{\sqrt{R h_{d}}}\right)\right.\right. \\
& \left.\left.-2 \sqrt{\frac{R}{h_{d}}} \tan ^{-1}\left(\frac{x}{\sqrt{R h_{d}}}\right)\right)\right), \\
p_{d} & =\left(k_{f d}-\sigma_{d}\right) \frac{h k_{f}}{h_{d} k_{f d}} \exp \left(u \left(2 \sqrt{\frac{R}{h_{d}}} \tan ^{-1}\left(\frac{x}{\sqrt{R h_{d}}}\right)\right.\right. \\
& \left.\left.-2 \sqrt{\frac{R}{h_{d}}} \tan ^{-1}\left(\frac{x_{d}}{\sqrt{R h_{d}}}\right)\right)\right) .
\end{aligned}
$$
follows:

Letting $p_{e}=p_{d}$, the neutral point can be formulated as

$$
\begin{aligned}
x_{n} & =\sqrt{R h_{d}} \tan \left\{\frac { 1 } { 4 } \sqrt { \frac { h _ { d } } { R } } \left(2 \sqrt{\frac{R}{h_{d}}} \tan ^{-1}\left(\frac{x_{e}}{\sqrt{R h_{d}}}\right)\right.\right. \\
& +2 \sqrt{\frac{R}{h_{d}}} \tan ^{-1}\left(\frac{x_{d}}{\sqrt{R h_{d}}}\right) \\
& \left.\left.-\frac{1}{\mu} \ln \left(\frac{k_{f d}-\sigma_{d}}{k_{f e}-\sigma_{e}} \frac{h_{e} k_{f e}}{h_{d} k_{f d}}\right)\right)\right\} .
\end{aligned}
$$

By integrating the rolling stresses, the rolling force can be determined:

$$
F=\int_{x_{n}}^{x_{e}} p_{e} d x+\int_{x_{d}}^{x_{n}} p_{d} d x
$$

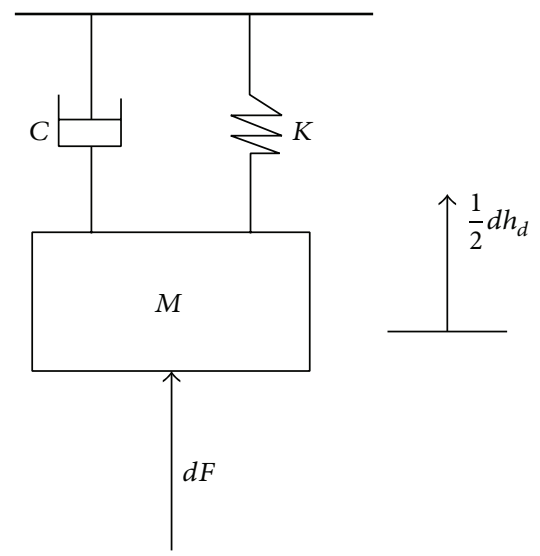

FIGURE 3: Mill stand structure model.

The dynamic rolling process model can be obtained by utilizing the first-order Taylor expansion:

$$
\begin{aligned}
& d F=F_{1} d h_{d}+F_{2} d \dot{h}_{d}+F_{3} d \sigma_{e}+F_{4} d \sigma_{d}+F_{5} d h_{e}, \\
& d v_{e}=P_{1} d h_{d}+P_{2} d \dot{h}_{d}+P_{3} d \sigma_{e}+P_{4} d \sigma_{d}+P_{5} d h_{e}, \\
& d v_{d}=Q_{1} d h_{d}+Q_{2} d \dot{h}_{d}+Q_{3} d \sigma_{e}+Q_{4} d \sigma_{d}+Q_{5} d h_{e} .
\end{aligned}
$$

$F_{j}, P_{j}, Q_{j}, j=1,2,3,4,5$, are the partial derivatives of $F, v_{e}, v_{d}$ with respect to $h_{d}, \dot{h}_{d}, \sigma_{e}, \sigma_{d}, h_{e}$, respectively. The calculation of $F_{j}, P_{j}, Q_{j}, j=1,2,3,4,5$, can be found in the Appendix.

Considering the work roll flattening effect in rolling, the equivalent work roll radius is calculated by employing the Hitchcock formula:

$$
R=R_{w}\left(1+\frac{16\left(1-\lambda^{2}\right)}{\pi E_{w}} \frac{F}{r}\right)
$$

where $R_{w}$ is initial work roll radius, $\lambda$ is Poisson's ratio for the work roll material, $F$ is rolling pressure, $r$ is reduction, and $E_{w}$ is elasticity modulus of work roll material.

Chatter in rolling is the result of the interaction between rolling process and mill stand structure. The rolling process model and stand structure model are coupled together through mechanical rolling parameters. A one degree of freedom mill stand structure model is shown in Figure 3.

By coupling the rolling process model and stand structure model together, the single stand vibration model is as follows:

$$
\begin{aligned}
M d \ddot{h}_{d}+C d \dot{h}_{d}+K d h_{d} & =2 w d F \\
d \dot{\sigma}_{e} & =\frac{E}{L_{e}} d v_{e}, \\
d \sigma_{d} & =-\frac{E}{L_{d}} d v_{d},
\end{aligned}
$$

where $L_{e}$ is the distance between the stand and the upstream stand and $L_{d}$ is the distance between the stand and downstream stand. 
TABLE 1: The initial rolling process parameters for the 1st and 2nd stand.

\begin{tabular}{lcccccc}
\hline$h_{e, 1}(\mathrm{~mm})$ & $h_{d, 1}$ & $h_{e, 2}(\mathrm{~mm})$ & $h_{d, 2}(\mathrm{~mm})$ & $\sigma_{e, 1}(\mathrm{Mpa})$ & $\sigma_{d, 1}(\mathrm{Mpa})$ & $\sigma_{e, 2}(\mathrm{Mpa})$ \\
\hline 0.45 & 0.28 & 0.28 & 0.19 & 137 & 137 & 137 \\
$\sigma_{d, 2}(\mathrm{Mpa})$ & $u_{1}$ & $u_{2}$ & $R_{w, 1}(\mathrm{~mm})$ & $R_{w, 2}(\mathrm{~mm})$ & $\sigma_{0}(\mathrm{Mpa})$ & $A$ \\
98 & 0.018 & 0.015 & 276 & 291 & 811.6 & 811.6 \\
$n$ & $L_{e, 1}(\mathrm{~m})$ & $L_{e, 2}(\mathrm{~m})$ & $L_{d, 2}(\mathrm{~m})$ & $E_{w}(\mathrm{Gpa})$ & $E(\mathrm{Gpa})$ & 210 \\
0.24 & 4.5 & 4.5 & 4.5 & 210 & 0.9 \\
\hline
\end{tabular}

The regenerative chatter model for a two-stand rolling mill is as follows:

$$
\begin{aligned}
M d \ddot{h}_{d, 1}+C d \dot{h}_{d, 1}+K d h_{d, 1} & =2 w d F_{1}, \\
d \dot{\sigma}_{e, 1} & =\frac{E}{L_{e, 1}} d v_{e, 1}, \\
d \dot{\sigma}_{d, 1} & =\frac{E}{L_{e, 2}}\left(d v_{e, 2}-d v_{d, 1}\right), \\
M d \ddot{h}_{d, 2}+C d \dot{h}_{d, 2}+K d h_{d, 2} & =2 w d F_{2}, \\
d \dot{\sigma}_{d, 2} & =-\frac{E}{L_{d, 2}} d v_{d, 2},
\end{aligned}
$$

where the second subscripts stand for the number of stands, $E$ is the elasticity modulus of roll piece material, and $w$ is the rolled strip width. The rolled strip width spread is neglected. So $w$ is constant.

The relationship between the 2 nd stand entry strip gauge variation and the 1st stand exit strip gauge variation is as follows:

$$
d h_{e, 2}(t)=d h_{d, 1}(t-\tau),
$$

where $\tau$ is the delay time, decided by the interstand distance and the entry velocity of 2 nd stand:

$$
\tau=\frac{L_{e, 2}}{v_{e, 2}} .
$$

The initial rolling process parameters for the 1st and 2 nd stand come from [7] and are shown in Table 1.

To explore the effects of interstand coupling factors on regenerative chatter in detail, four models were built in this paper. The first one is a single stand vibration model. The second one is a two-stand regenerative chatter model which only considers the interstand tension coupling effect. The third one is a two-stand regenerative chatter model which considers the interstand tension coupling effect and the strip gauge variation passed on to next stand but neglects the delay time. The fourth one is a two-stand regenerative chatter model which considers the interstand tension coupling effect and the strip gauge variation passed on to next stand with time delay effect.

\section{Stability Analysis}

3.1. Stability Criterion. To study the stabilities of the four models proposed in Section 2, different stability criteria have to be used to calculate the critical velocity for each model. The first three models are nondelay differential systems. Their critical velocities can be calculated by employing the Lyapunov indirect method. According to the Lyapunov indirect method, for a linear system $\dot{x}=A x$, if all the real parts of eigenvalues of matrix $A$ are negative, the system is stable, if not, the system is unstable [13]. Based on this method, critical velocities of the first three models are obtained, namely, $34.82 \mathrm{~m} / \mathrm{s}$ for the single 2nd stand model, $36.00 \mathrm{~m} / \mathrm{s}$ for the second model, and $30.23 \mathrm{~m} / \mathrm{s}$ for the third model. Similar to the single 2 nd stand model, the critical velocity of the single 1st stand is $24.78 \mathrm{~m} / \mathrm{s}$.

The fourth model is a delay differential system. The stability criterion of time delay system is much more complex than nondelay system. The integral criterion is employed to analyze the fourth model. According to the integral criterion, if the following inequation is true, the delay differential system is asymptotic stable [14]:

$$
\int_{0}^{\infty} L(w)>\frac{(N-1)}{2} \pi
$$

where

$$
L(w)=\frac{R(w) S^{\prime}(w)-S(w) R^{\prime}(w)}{R(w)^{2}+S(w)^{2}} .
$$

$R(w)$ and $S(w)$ are the real and imaginary parts of the determinant of the system matrix, respectively. $N$ is the order of the system. For the fourth model, $N$ is 7 . The integration is calculated with the help of MATLAB. When the linear velocity of the $2 \mathrm{nd}$ stand is $29.2 \mathrm{~m} / \mathrm{s}$,

$$
\int_{0}^{5000} L(w)=10.7
$$

When the linear velocity of the $2 \mathrm{nd}$ stand is $29.3 \mathrm{~m} / \mathrm{s}$,

$$
\int_{0}^{5000} L(w)=4.5
$$

So the critical velocity of fourth model is about $29.25 \mathrm{~m} / \mathrm{s}$.

Comparing the critical velocities of the four models, it can be concluded that the interstand tension has just a little effect on the critical velocity of the chatter model. The strip gauge variation passed on between stands reduces the critical velocity dramatically. However, the time delay effect as an independent factor on critical velocity is very limited. 


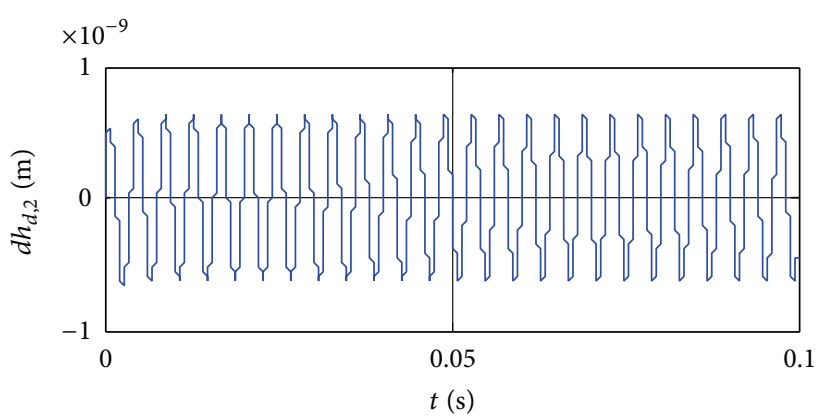

(a)

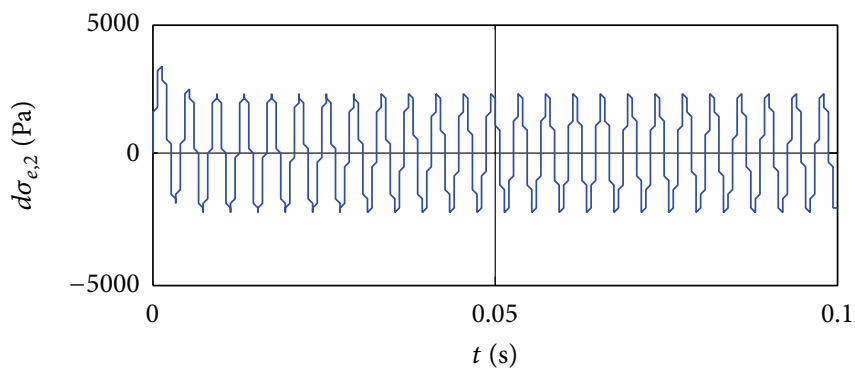

(b)

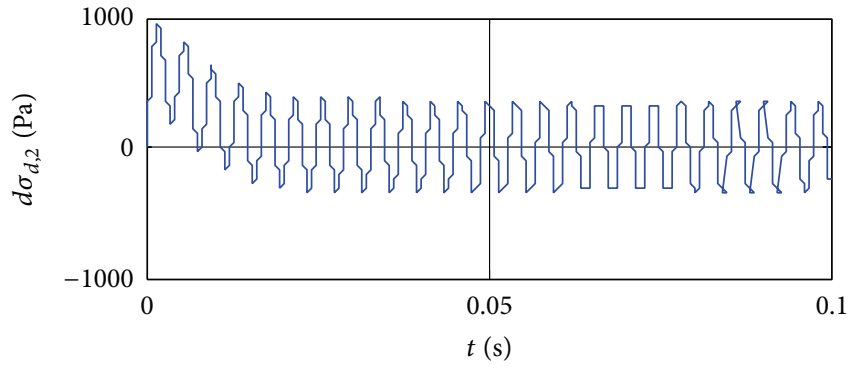

(c)

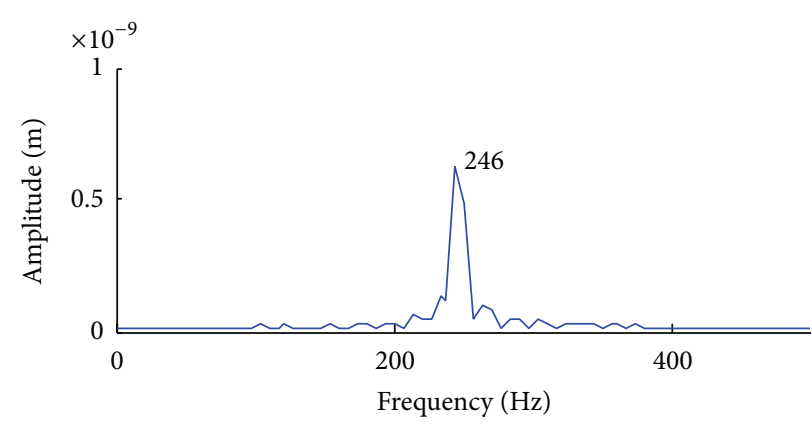

(d)

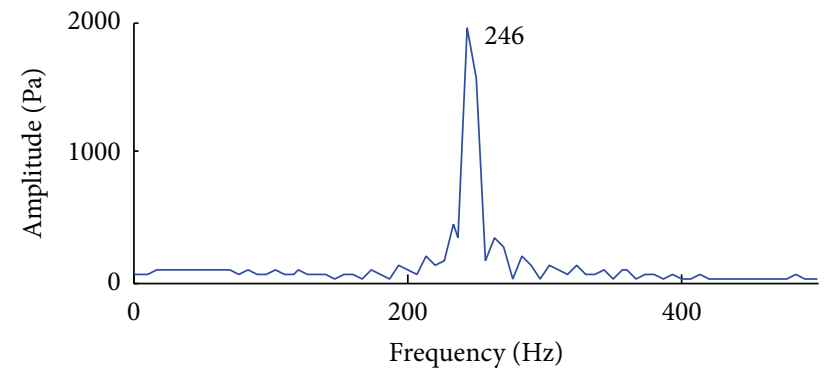

(e)

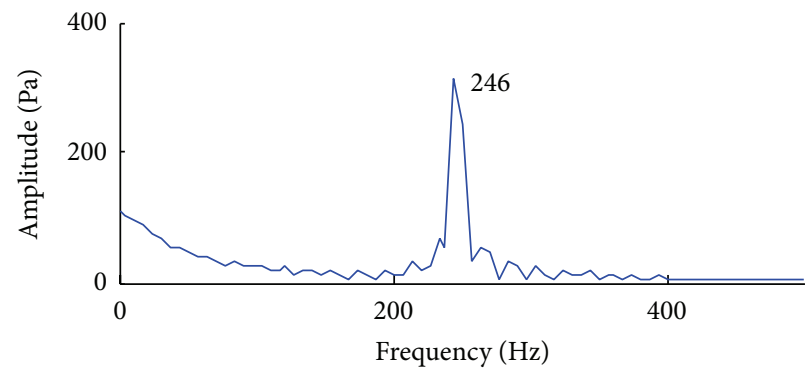

(f)

FIGURE 4: Time and frequency domain of the single 2nd stand when $v_{r, 2}=34.82 \mathrm{~m} / \mathrm{s}$. ((a) and (d)) work roll; ((b) and (e)) entry tension; ((c) and (f)) exit tension.

3.2. Simulation and Analysis. To study the regenerative chatter mechanism and relationship between stands in detail, time and frequency domain simulations of the four models were conducted. As shown in Figure 4, the single 2nd stand vibrates periodically when $v_{r, 2}$ is $34.82 \mathrm{~m} / \mathrm{s}$ and the frequency is $246 \mathrm{~Hz}$. Similarly, the single 1st stand vibrates periodically when $v_{r, 1}$ is $24.78 \mathrm{~m} / \mathrm{s}$ and the frequency is $209 \mathrm{~Hz}$ as shown in Figure 5.

The second model only considers the interstand tension coupling effect between stands. As can been seen in Figure 6, the 1st stand takes on periodic oscillation state and the frequency is $209 \mathrm{~Hz}$. It is the same with the single 1st stand model. The beat phenomena appear in the 2 nd stand and the interstand tension. The frequencies are $209 \mathrm{~Hz}$ and $251 \mathrm{~Hz}$. $209 \mathrm{~Hz}$ is the frequency of the 1st stand and $251 \mathrm{~Hz}$ is approximate to the frequency of the 2 nd stand. It is obvious that the beat phenomena are caused by the interstand tension coupling effect between the 1st stand and 2nd stand. Besides, the amplitude of 2 nd stand is far less than the 1st stand.
It suggests that the vibration in 2 nd stand raised by the interstand tension variation is not violent.

The third model considers the interstand tension coupling effect and the strip gauge variation passed on to the next stand but neglects the time delay effect. As shown in Figure 7, the beat phenomena in the second model disappear. The frequency of the 1st stand, the 2nd stand, and the interstand tension are all $212 \mathrm{~Hz}$. The amplitudes of the 1st and $2 \mathrm{nd}$ stand are in the same magnitude. It indicates that the strip gauge variation passed on to the next stand makes the 2 nd stand vibrate more violently.

The fourth model considers the interstand tension coupling effect between stands, the strip gauge variation passed on to the next stand, and the time delay effect. As shown in Figure 8, the time domain of 1st stand, 2nd stand, and the interstand tension are all gourd-shaped, which consist with the test results in [1]. The time domain of the 2 nd stand lags behind the 1st stand by the delay time. Due to the time delay effect, the frequency domain of the fourth model is more 


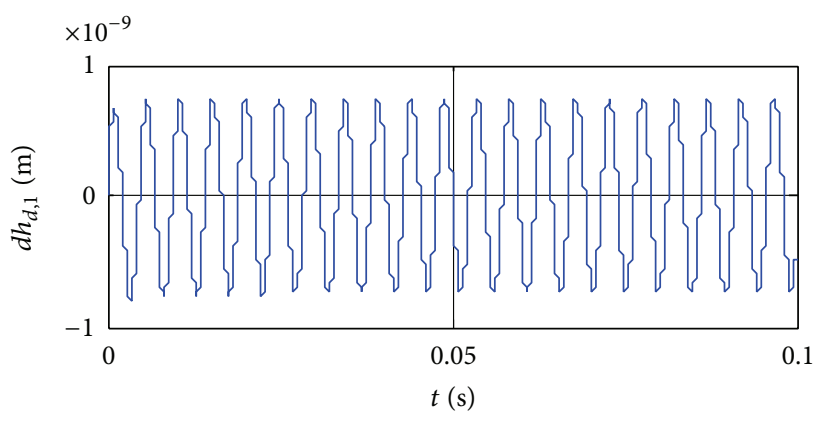

(a)

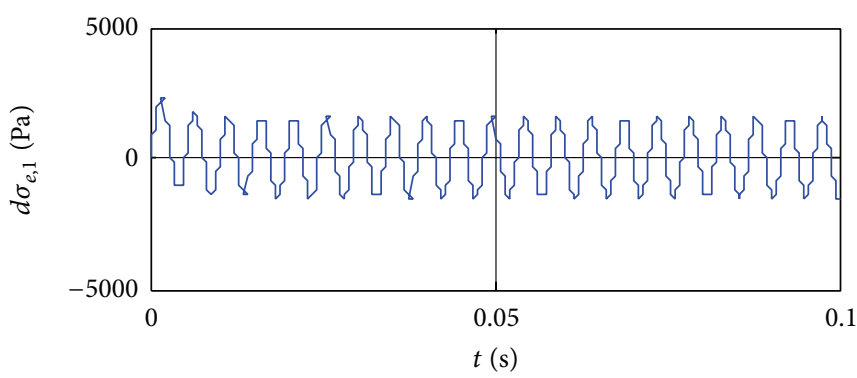

(b)

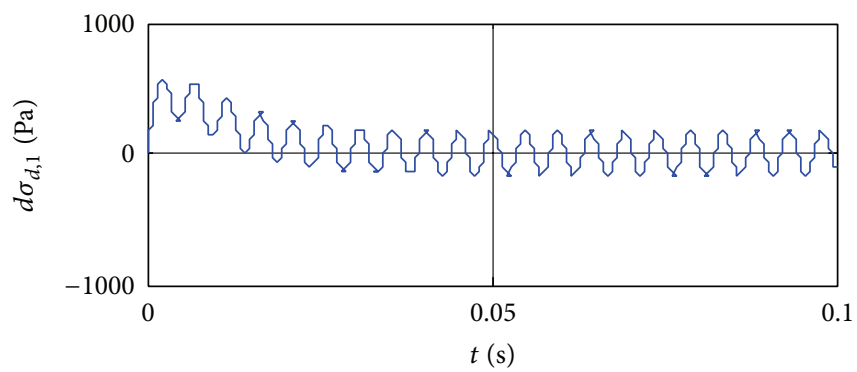

(c)

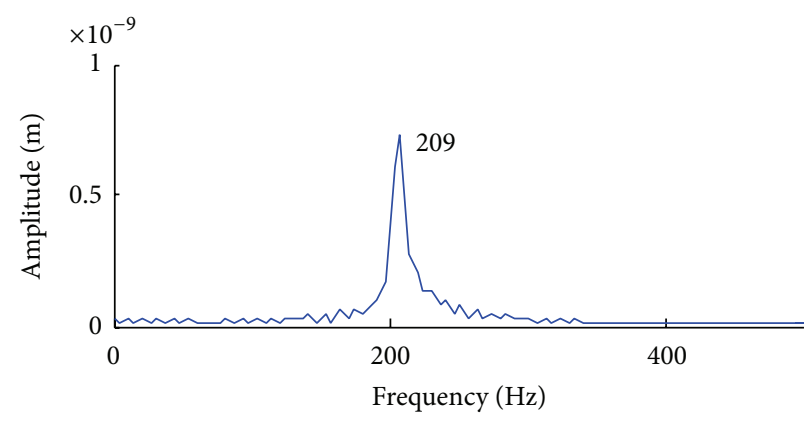

(d)

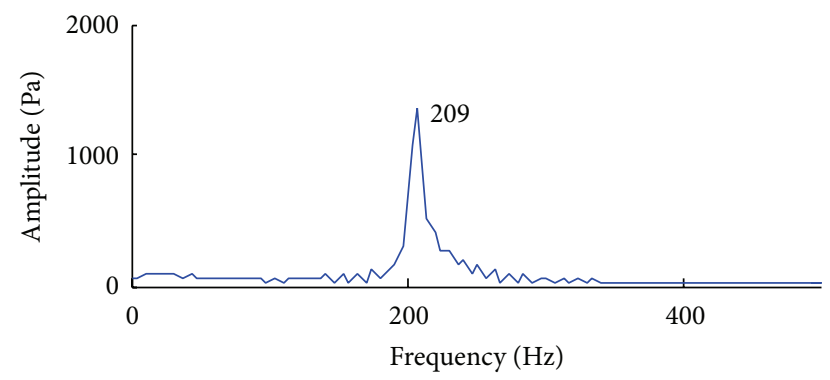

(e)

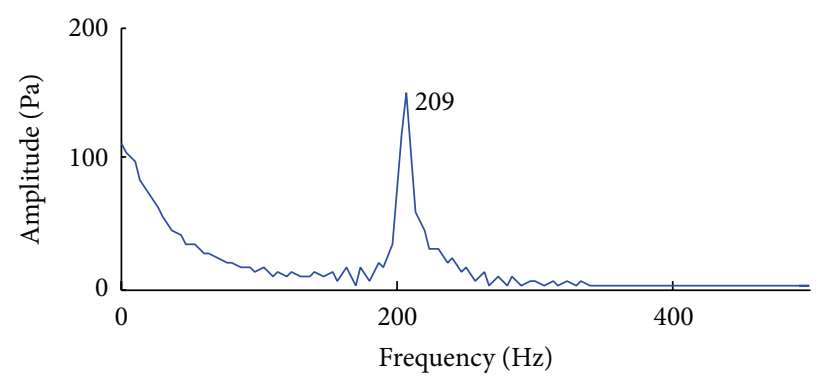

(f)

FIGURE 5: Time and frequency domain of the single 1st stand when $v_{r, 1}=24.78 \mathrm{~m} / \mathrm{s}$. ((a) and (d)) work roll; ((b) and (e)) entry tension; ((c) and (f)) exit tension.

complex than the third model. The main frequency is $209 \mathrm{~Hz}$, a little smaller than the third model, but still in the range of the third octave mode chatter.

Comparing the above four models, a more detailed explanation for regenerative chatter mechanism in rolling can be presented. Consequent stands in tandem rolling mills are coupled together through rolled piece. One of these stands becomes unstable and oscillates first, for example, the $i$ th stand. The $i$ th stand vibration gives rise to the interstand tension vibration. The interstand vibration makes the $i+1$ th stand vibrate gently at once. The amplitude of the $i+1$ th stand is far smaller than that of the $i$ th stand by this time. But the strip gauge variation generated by the $i$ th stand is passed on to the $i+1$ th stand after delay time. It aggravates the vibration of the $i+1$ th stand and makes the $i$ th and $i+1$ th stand vibrate in the same amplitude. The oscillation of the $i+1$ th stand intensifies vibration of the interstand tension and finally makes the $i$ th stand vibrate again.

It can be concluded from the above analysis that time delay effect as an independent factor has very limited effects on both critical velocity and chatter frequency, while making the stability analysis more complex. But it does not mean that time delay effect can be neglected when modeling the rolling system. Enough works have been done to compare the first, second, and the fourth model in [4]. To study the time delay effect as a single factor on multistand rolling system, stability analysis comparison of the third model and fourth model was done in the next section. To simplify the writing mode, the third model is called the nondelay system and the fourth model is called the delay system.

\section{Effects of Rolling Process Parameters}

4.1. Effects of Friction. Stability of a single stand is very sensitive to friction. The critical velocity of a single stand grows rapidly with the increase of friction coefficient [2, 7]. But things are different for multistand systems, as shown in Figure 9.

When $u_{1}$ is small enough, stability of the 1st stand gets worse and it becomes more unstable than the 2nd stand. 


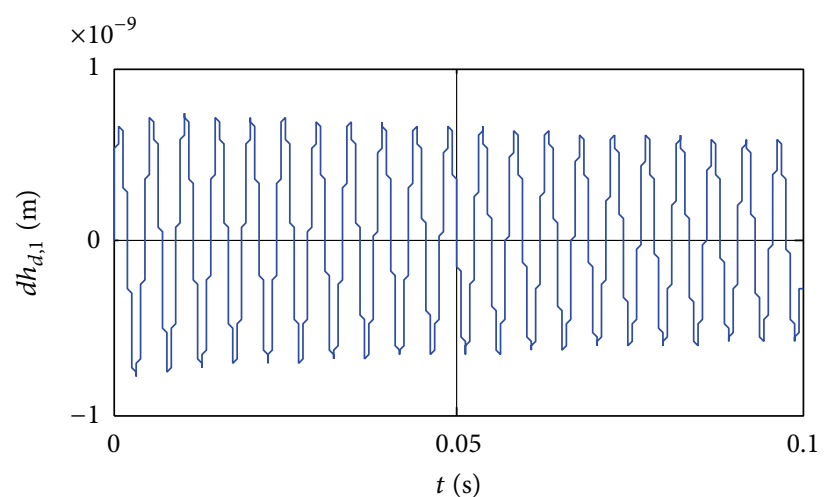

(a)

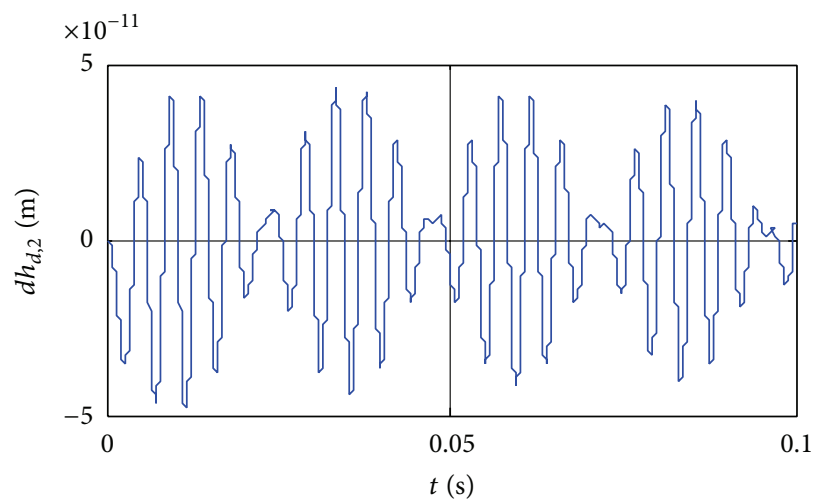

(b)

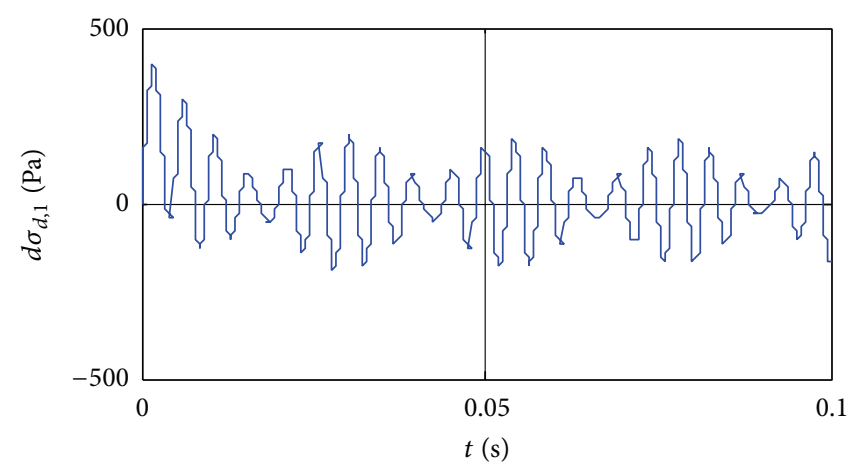

(c)

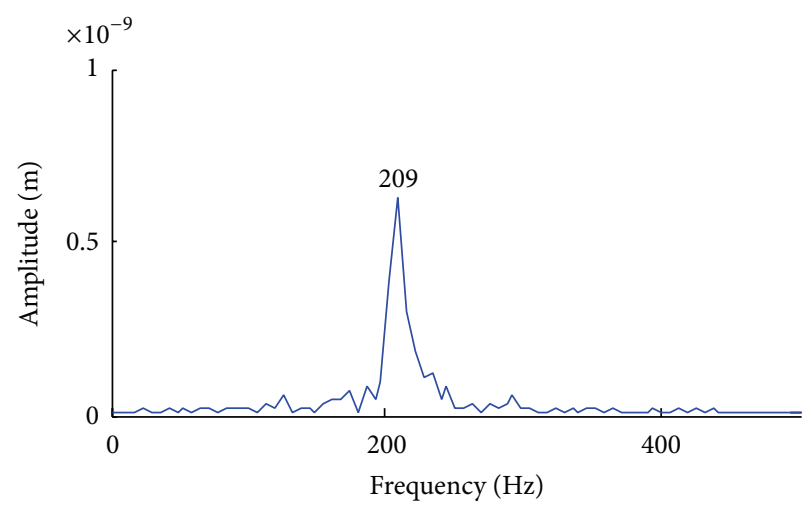

(d)

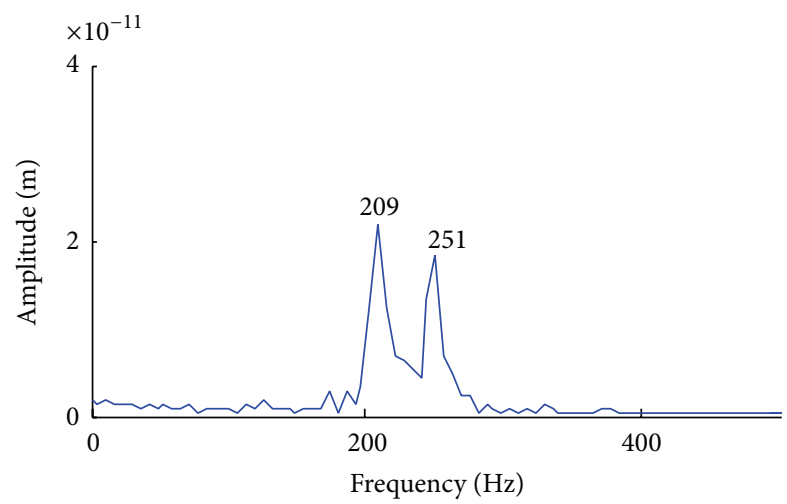

(e)

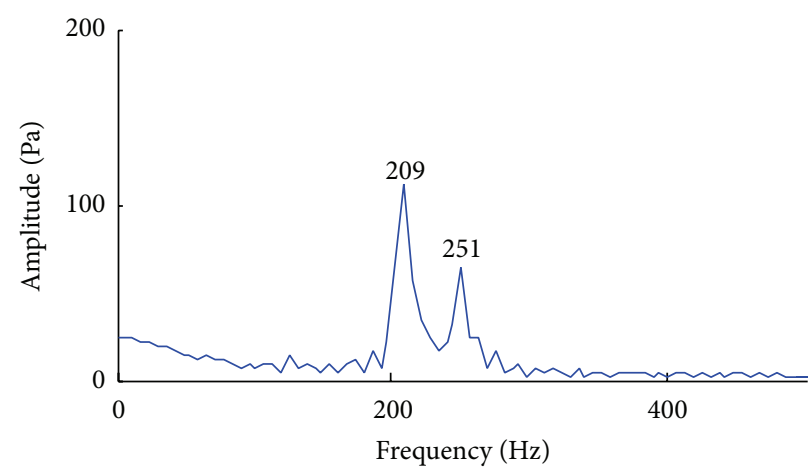

(f)

FIGURE 6: The time and frequency domain of the second model $v_{r, 2}=36.00 \mathrm{~m} / \mathrm{s}$. ((a) and (d)) 1st stand work roll; ((b) and (e)) 2nd stand work roll; ((c) and (f)) interstand tension.

For example, as shown in Table 2, when $u_{1}$ is 0.014 , the critical velocity of single 1st stand is $22.9 \mathrm{~m} / \mathrm{s}$. According to the principle of mass conservation, the corresponding velocity of 2 nd stand is $33.1 \mathrm{~m} / \mathrm{s}$, which is smaller than the single 2nd stand critical velocity $34.8 \mathrm{~m} / \mathrm{s}$. The 1st stand becomes unstable before the 2 nd stand. The critical velocity of the twostand system is determined by the 1st stand. As $u_{1}$ increases, the 1st stand becomes more stable and critical velocity of the two-stand system increases sharply until $u_{1}$ reaches a certain point.
TABLE 2: The critical velocities for different stands when $u_{1}$ changes.

\begin{tabular}{lcc}
\hline$u_{1}$ & 0.014 & 0.018 \\
\hline $\begin{array}{l}\text { Critical velocity of single 1st stand } v_{c, 1} \\
(\mathrm{~m} / \mathrm{s})\end{array}$ & 22.9 & 24.8 \\
$\begin{array}{l}\text { Corresponding critical velocity of } \\
\text { single 2nd stand } v_{c, 2}(\mathrm{~m} / \mathrm{s})\end{array}$ & 33.1 & 36.3 \\
$\begin{array}{l}\text { Critical velocity of single 2nd stand } v_{c, 2} \\
(\mathrm{~m} / \mathrm{s})\end{array}$ & 34.8 & 34.8 \\
More unstable stand & 1st stand & 2nd stand
\end{tabular}




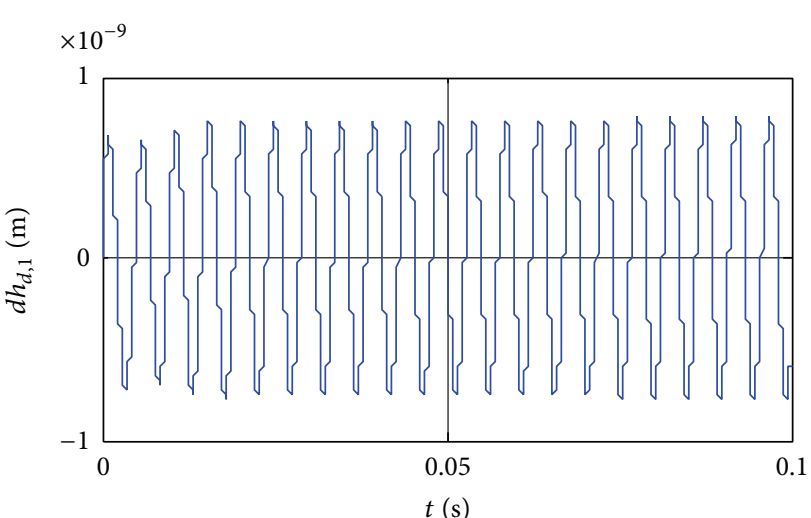

(a)

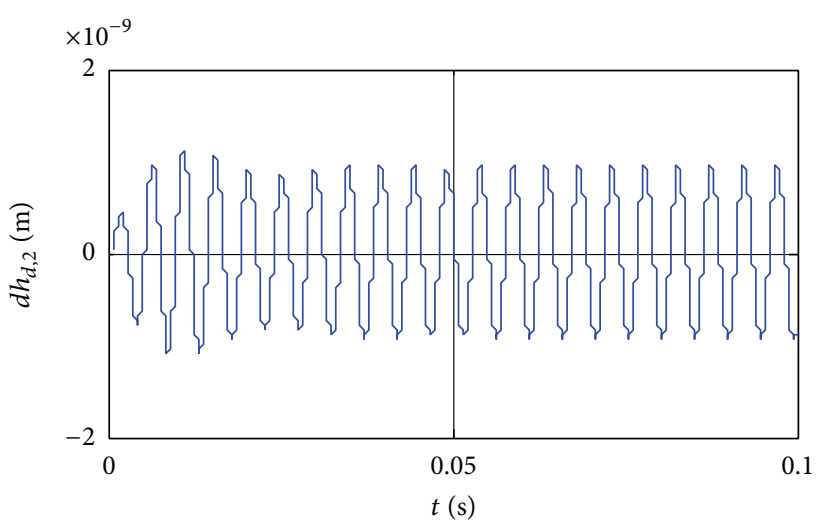

(b)

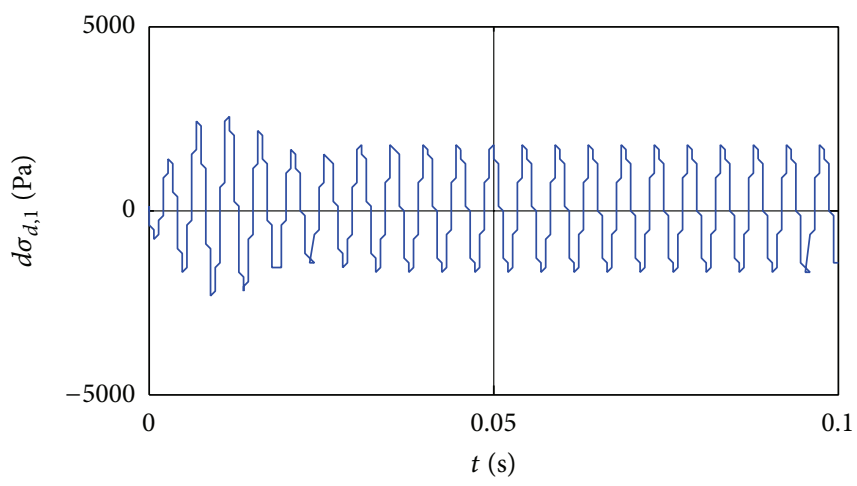

(c)

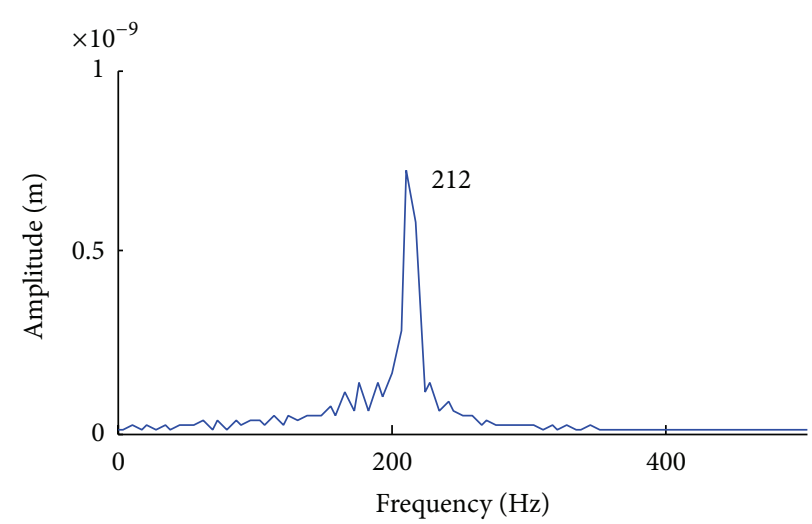

(d)

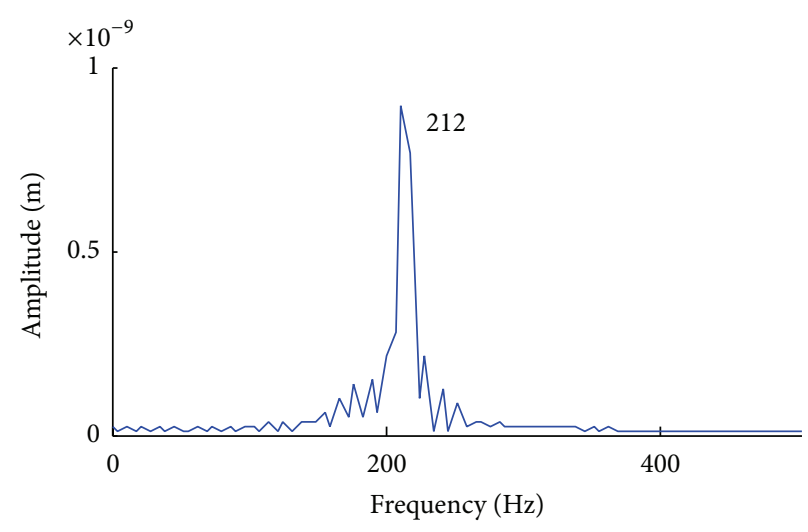

(e)

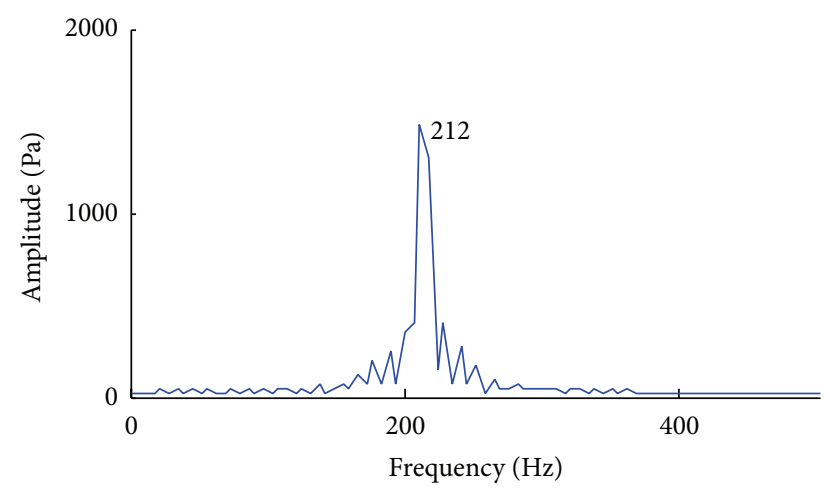

(f)

Figure 7: The time and frequency domain of the third model when $v_{r, 2}=30.23 \mathrm{~m} / \mathrm{s}$. ((a) and (d)) 1st stand work roll; ((b) and (e)) 2nd stand work roll; ((c) and (f)) interstand tension.

When $u_{1}$ is big enough, 2 nd stand becomes more unstable than 1st stand. For example, as shown in Table 2, when $u_{1}$ is 0.018 , the critical velocity of the single 1st stand goes up to $24.8 \mathrm{~m} / \mathrm{s}$ and the corresponding velocity of the single $2 \mathrm{nd}$ stand rises to $36.3 \mathrm{~m} / \mathrm{s}$, which is bigger than critical velocity of the 2 nd stand. The 2 nd stand becomes unstable first. The critical velocity of the two-stand system is determined by the 2nd stand. As $u_{1}$ increases, the 1st stand becomes more stable, but it has little effect on the 2nd stand. The stability of 2nd stand is much worse than the 1st stand, so the critical velocity of the two-stand system goes down, as shown in Figure 9.
When $u_{1}$ goes up, the overall trend of critical velocities are the same for the delay system and nondelay system. There exists an optimal $u_{1}$, which relates to the maximum critical velocity, given that other rolling parameters remain unchanged. But the optimal $u_{1}$ values are different for the delay and nondelay system. The optimal $u_{1}$ for the delay system is about 0.016 , while the optimal $u_{1}$ for the nondelay system is about 0.02 . Critical velocities for the delay system are smaller than the nondelay system, especially when $u_{1}$ is larger. It can be explained by the idea that time delay effect has a far greater impact on 2nd stand than 1st stand, as the strip 


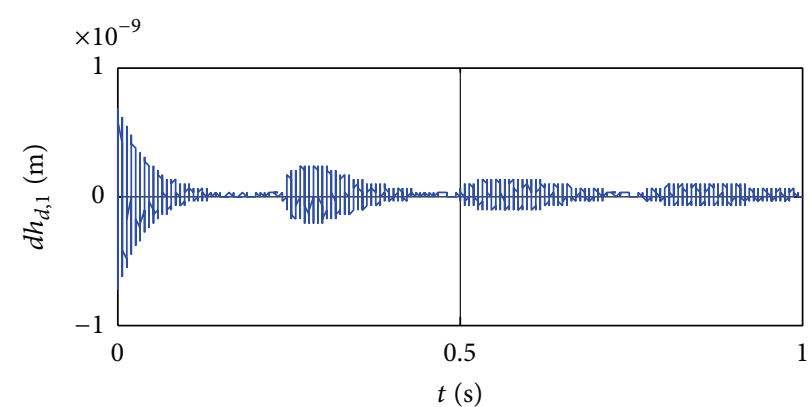

(a)

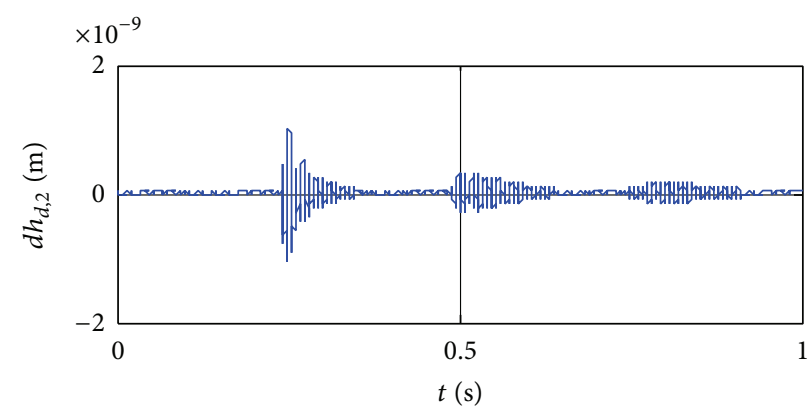

(b)

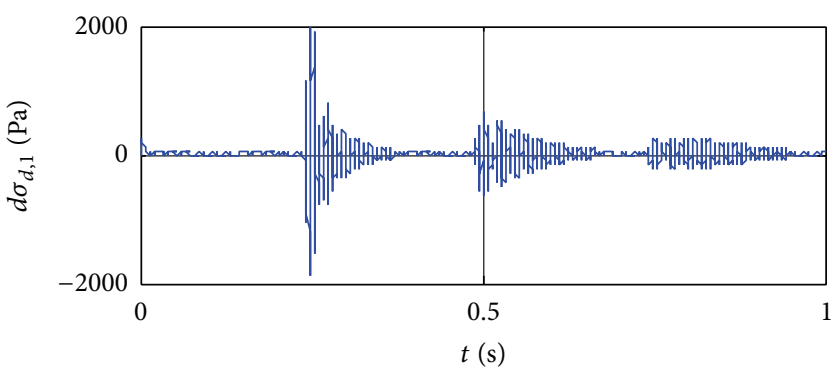

(c)

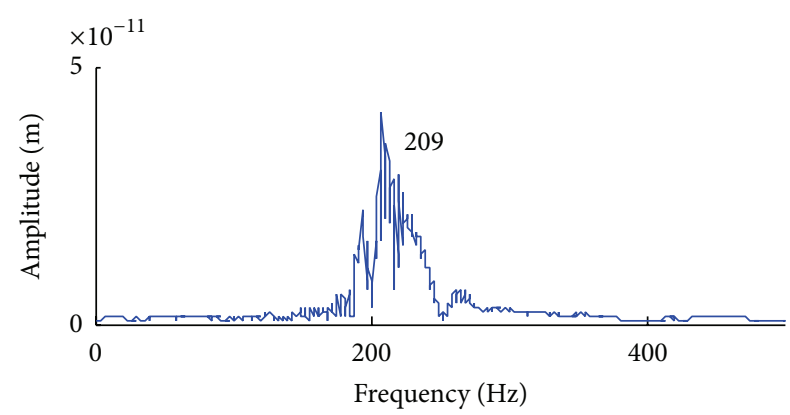

(d)

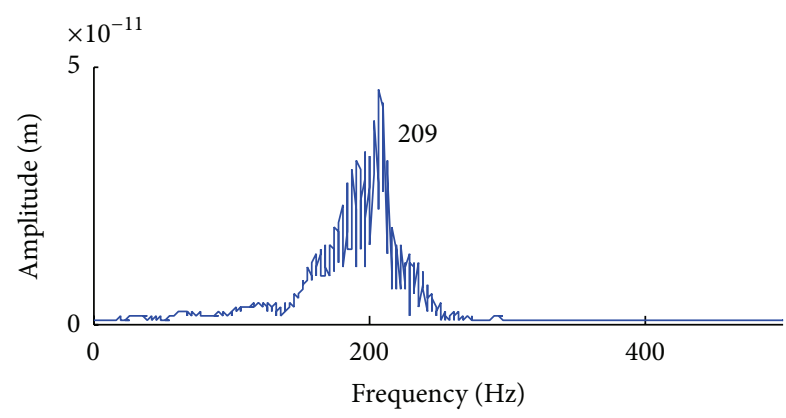

(e)

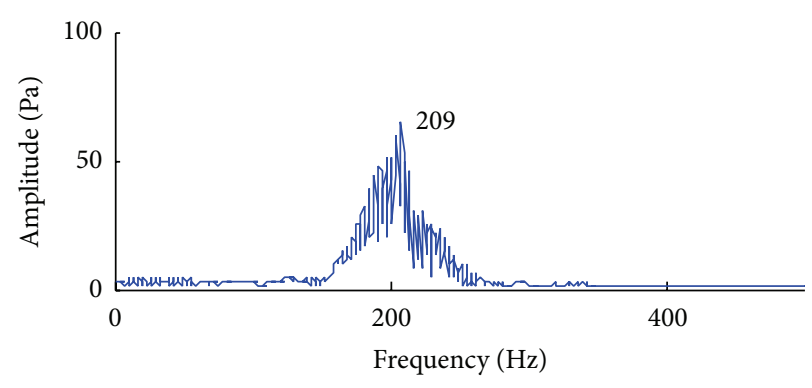

(f)

FIGURE 8: The time and frequency domain of the fourth model when $v_{r, 2}=29.25 \mathrm{~m} / \mathrm{s}$. ((a) and (d)) 1st stand work roll; ((b) and (e)) 2nd stand work roll; ((c) and (f)) interstand tension.

gauge variation generated in the 1st stand is passed on to the 2nd stand with delay time but not in the opposite direction.

Figure 10 demonstrates the critical velocities for the delay system and nondelay system when the friction coefficient of the 2 nd stand increases. The critical velocity changing trend is much simpler. When $u_{2}$ is small enough, the 2 nd stand is more unstable and the critical velocity increases as $u_{2}$ goes up. When $u_{2}$ is big enough, the stability of the whole system becomes better as $u_{2}$ goes up. The critical velocities for the delay system and nondelay system are almost the same. When $u_{2}$ is relatively small, the critical velocity of the time delay system is slightly smaller than that of the nondelay system. The smaller the $u_{2}$ is, the more unstable and sensitive to $u_{2}$ the time delay system is.

4.2. Effects of Interstand Tension. The critical velocity for a single stand decreases as the entry tension and exit tension increase. But the critical velocity is more sensitive to the entry tension due to the fact that the entry zone is much longer that the exit zone [2].

$\sigma_{d, 1}$ is the intertension between the 1st and 2nd stand, namely, the exit tension of the 1st stand and the entry tension of the 2 nd stand. The stability of the 1st and 2 nd stand both goes worse with the increase of $\sigma_{d, 1}$. Therefore, the critical velocities of the delay and nondelay system both fall off as $\sigma_{d, 1}$ increases, as shown in Figure 11. But the stability of the 2 nd stand is more sensitive to $\sigma_{d, 1}$, as $\sigma_{d, 1}$ is the entry tension for the 2 nd stand. As can been seen from Table 3 , when $\sigma_{d, 1}$ is rather small, the 1st stand becomes unstable first, and the critical velocity of the system is decided by the 1st stand. The critical velocities decrease slowly as $\sigma_{d, 1}$ is the exit tension of the 1st stand. But when $\sigma_{d, 1}$ is big enough, the 2 nd stand becomes unstable first, and the critical velocity of the two-stand system is decided by the 2 nd stand. The critical velocities of the delay system decrease fast with the increase of $\sigma_{d, 1}$, because $\sigma_{d, 1}$ is the entry tension of the 2 nd stand. 


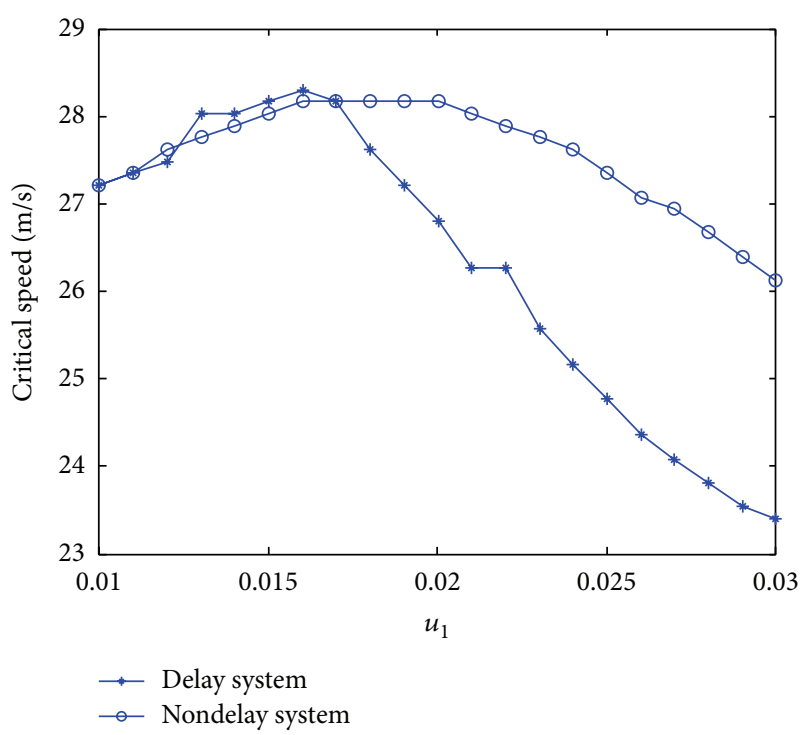

FIgURE 9: Comparison of stability charts for $u_{1}$.

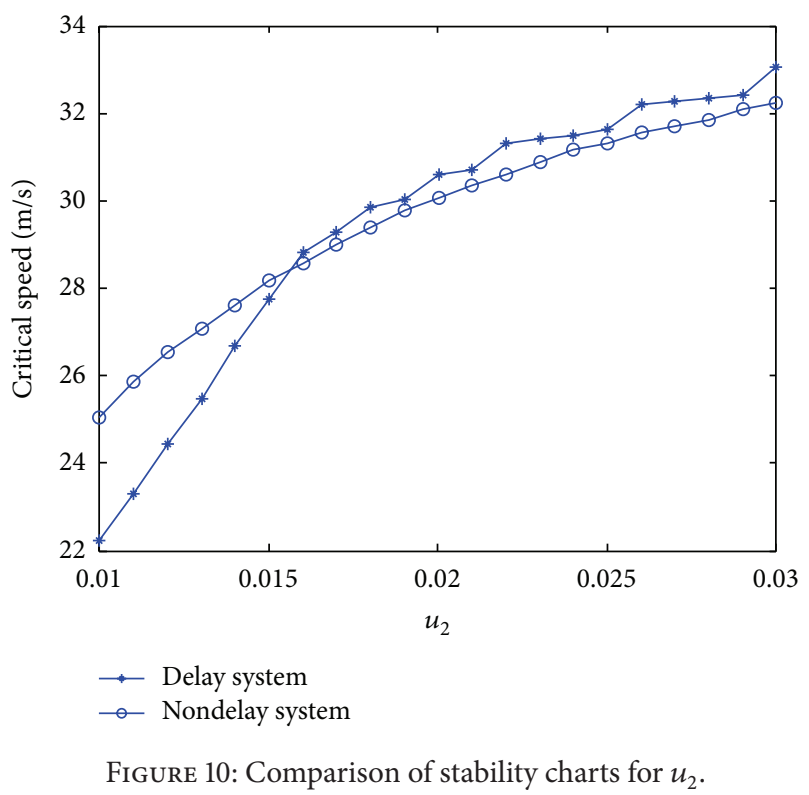

When considering the time delay effect, the critical velocity gets smaller and more sensitive to $\sigma_{d, 1}$.

4.3. Effects of Interstand Distance. Interstand tension variation becomes more gentle with the increase of interstand distance. And so the stability of mill stand becomes better [2]. But it is more complex to multistand system. $L_{e, 2}$ is the distance between the 1st and 2nd stand. If $L_{e, 2}$ is changed, the interstand tension variation and the delay time are both changed. As shown in Figure 12, for time delay system, with the increase of $L_{e, 2}$, the interstand tension variation decreases and critical velocity of delay system rises. Meantime, the delay time becomes larger and critical velocity decreases. So the critical velocities of time delay system form a wavy pattern of rising.

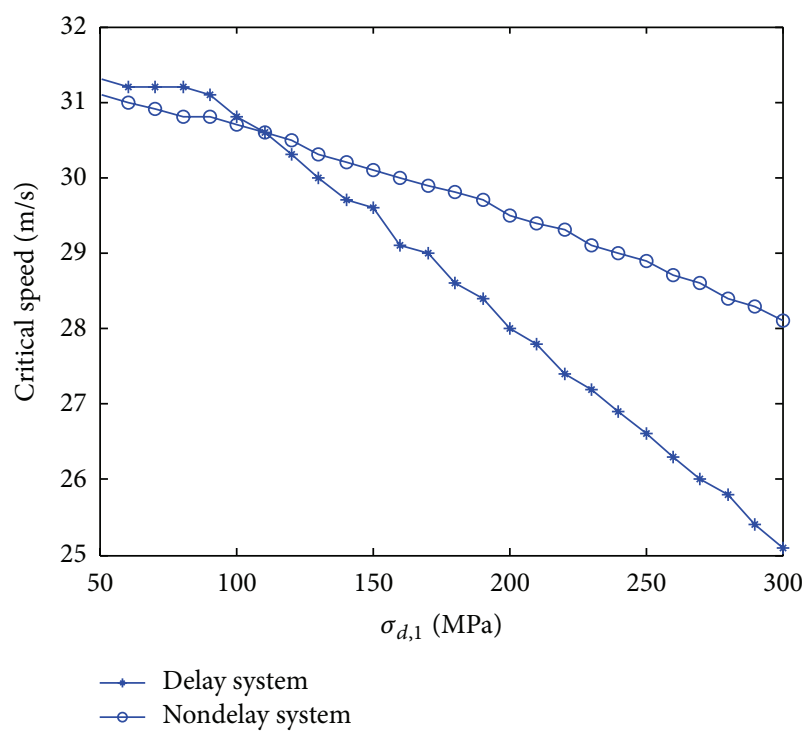

FIGURE 11: Comparison of stability charts for $\sigma_{d, 1}$.

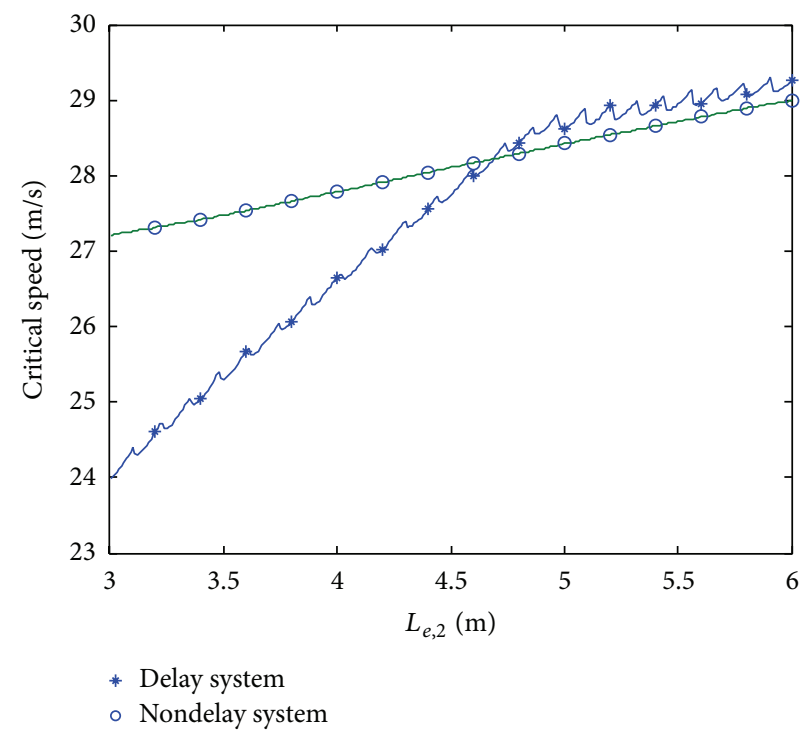

FIgURE 12: Comparison of stability charts for $L_{e, 2}$.

TABle 3: The critical velocities for different stands when $\sigma_{d, 1}$ changes.

\begin{tabular}{|c|c|c|}
\hline$\sigma_{d, 1}(\mathrm{Mpa})$ & 60 & 250 \\
\hline Critical velocity of single 1st stand $v_{c, 1}(\mathrm{~m} / \mathrm{s})$ & 22.7 & 22.5 \\
\hline $\begin{array}{l}\text { Corresponding critical velocity of single 2nd } \\
\text { stand } v_{c, 2}(\mathrm{~m} / \mathrm{s})\end{array}$ & 32.6 & 33.5 \\
\hline $\begin{array}{l}\text { Critical velocity of single } 2 \mathrm{nd} \text { stand } v_{c, 2} \\
(\mathrm{~m} / \mathrm{s})\end{array}$ & 36.7 & 33.1 \\
\hline More unstable stand & 1st stand & 2nd stand \\
\hline
\end{tabular}

At first, the 2nd stand is more unstable than the 1st one. With the increase of $L_{e, 2}$, the critical velocities of the 1st and 2 nd stand both rise. But the critical velocity of 2 nd stand goes up much faster than the 1st stand, as $L_{e, 2}$ affects 


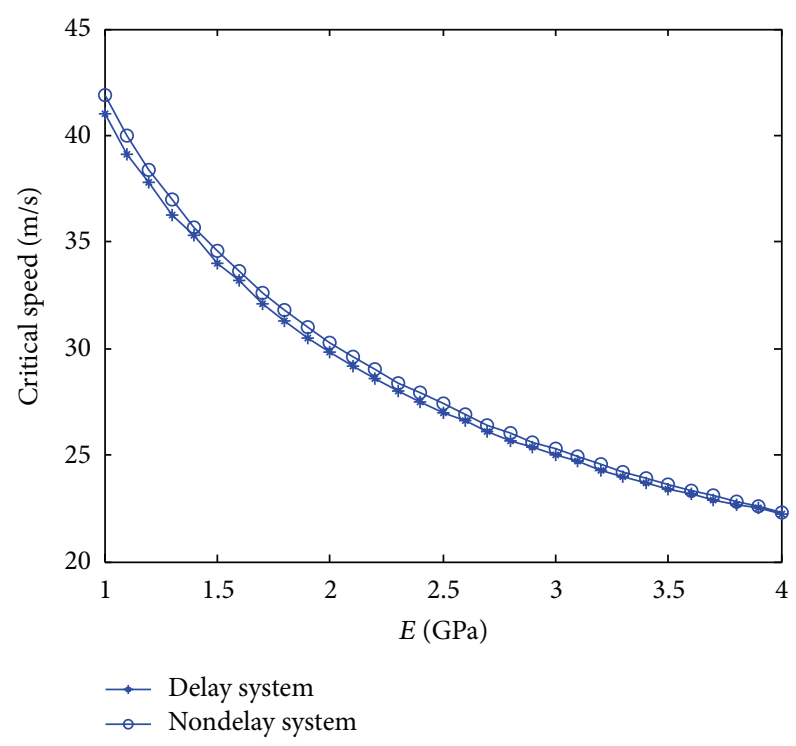

FIgURE 13: Comparison of stability charts for $E$.

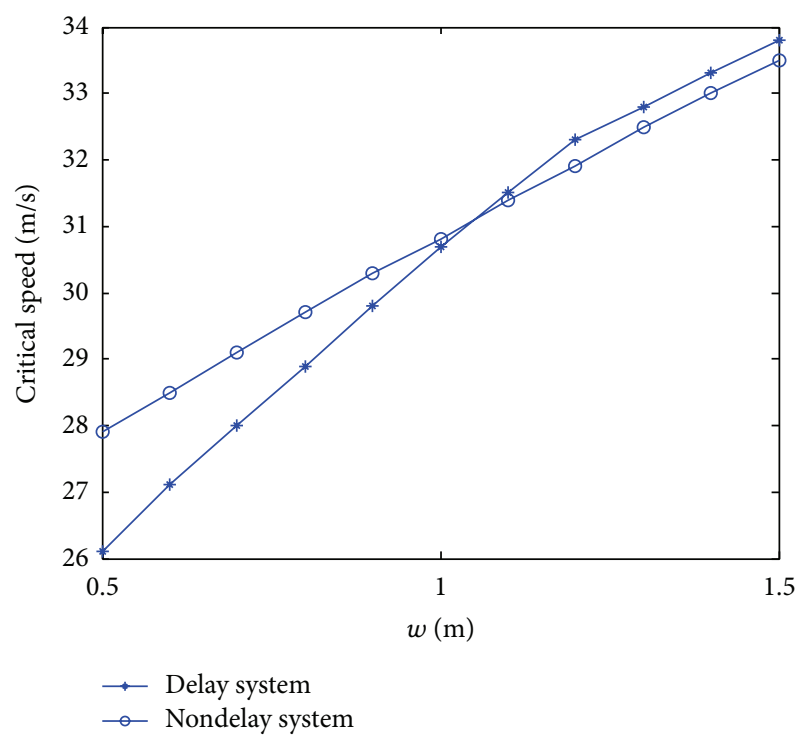

FIGURE 14: Comparison of stability charts for $w$.

the entry tension variation of 2 nd stand. The critical velocities of the nondelay and time delay system both rise fast. When $L_{e, 2}$ is bigger than a certain value, the 1st stand becomes unstable first. The rises of critical velocities for the nondelay and delay system both slow down, for $L_{e, 2}$ affects the exit tension variation of 1 st stand. It can been seen in Table 4 that when $L_{e, 2}$ is $3.5 \mathrm{~m}$, the 2nd stand goes to unstable first, but when $L_{e, 2}$ is $5.5 \mathrm{~m}$, chatter occurs in the 1st stand first. But the instability of the 1st stand occurs when $L_{e, 2}$ is quite bigger than nondelay system, for the delay time effect makes the 2 nd stand more unstable.

4.4. Effects of Strip Width and Strip Elastic Modulus. The critical velocity of a single stand system decreases with the increase of the strip elastic modulus and goes up along with

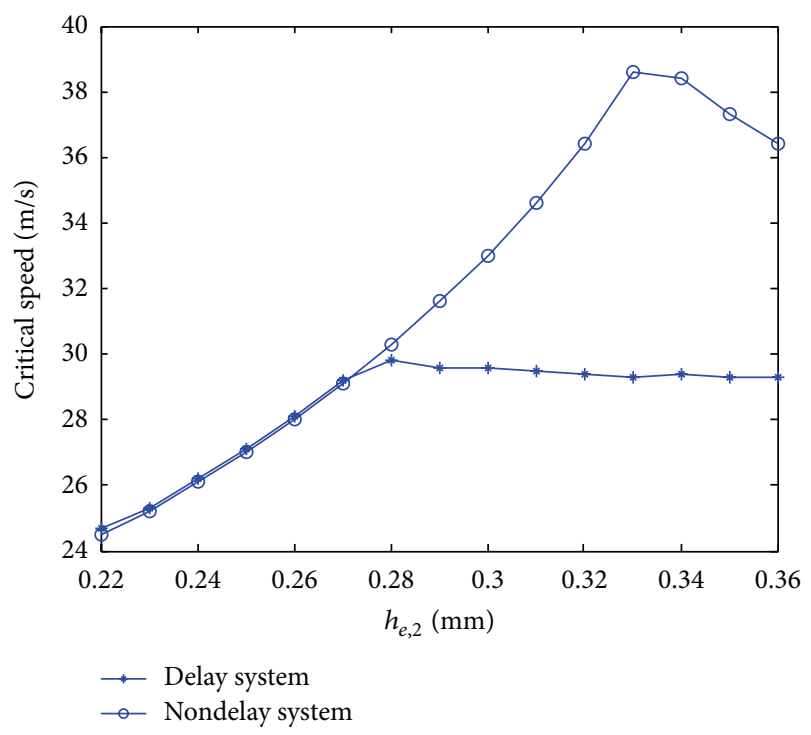

FIGURE 15: Comparison of stability charts for $h_{e, 2}$.

TABle 4: The critical velocities for different stands when $L_{e, 2}$ changes.

\begin{tabular}{lcc}
\hline$L_{e, 2}(\mathrm{~m} / \mathrm{s})$ & 3.5 & 5.5 \\
\hline $\begin{array}{l}\text { Critical velocity of single 1st stand } v_{c, 1} \\
(\mathrm{~m} / \mathrm{s})\end{array}$ & 24.63 & 24.87 \\
$\begin{array}{l}\text { Corresponding critical velocity of single } \\
\text { 2nd stand } v_{c, 2}(\mathrm{~m} / \mathrm{s})\end{array}$ & 36.05 & 36.40 \\
$\begin{array}{l}\text { Critical velocity of single 2nd stand } v_{c, 2} \\
(\mathrm{~m} / \mathrm{s})\end{array}$ & 31.38 & 37.89 \\
More unstable stand & 2nd stand & 1st stand \\
\hline
\end{tabular}

the increase of the strip width [2, 7]. As shown in Figures 13 and 14, it shows the same trend for both the time delay system and nondelay system. With the increase of strip elastic modulus, the critical velocities for the time delay system and nondelay system are almost the same. The latter is just a little bigger than the former. With the increasing strip width, the critical velocities for the time delay system and nondelay system both go up. But the critical velocities for the time delay system are a little more sensitive to the increase of strip width.

4.5. Effects of Reduction Allocation. It has been proved that the critical velocity for a single stand system decreases with the increase of the entry thickness, given that the exit thickness stays the same and increase with the rise of the exit thickness, given that the entry thickness remains the same [2]. But it is more complex for multistand system, as shown in Figure 15. Assuming that the entry strip thickness of the 1st stand and the exit strip thickness of the 2nd stand remain unaltered, the critical velocity would be changed if the entry thickness of the 2 nd stand, namely, $h_{e, 2}$, is changed.

If $h_{e, 2}$ is small enough, it means that exit strip thickness of the 1st stand decreases and entry strip thickness of the 2 nd stand increases. The 1st stand becomes unstable first. But as $h_{e, 2}$ rises, the 1 st stand reduction gets smaller while the 2 nd 
TABLE 5: The critical velocities for different stands when $h_{e, 2}$ changes.

\begin{tabular}{lcc}
\hline$h_{e, 2}(\mathrm{~mm})$ & 0.26 & 0.29 \\
\hline $\begin{array}{l}\text { Critical velocity of single 1st stand } v_{c, 1} \\
(\mathrm{~m} / \mathrm{s})\end{array}$ & 24.2 & 25.2 \\
$\begin{array}{l}\text { Corresponding critical velocity of single } \\
\text { 2nd stand } v_{c, 2}(\mathrm{~m} / \mathrm{s})\end{array}$ & 33.1 & 38.0 \\
$\begin{array}{l}\text { Critical velocity of single 2nd stand } v_{c, 2} \\
(\mathrm{~m} / \mathrm{s})\end{array}$ & 36.8 & 34.1 \\
More unstable stand & 1st stand & 2nd stand \\
\hline
\end{tabular}

stand reduction gets bigger. The 2 nd stand becomes more unstable than the 1st stand. As shown in Table 5, when $h_{e, 2}$ is $0.26 \mathrm{~mm}$, the 1st stand is more unstable. However, when $h_{e, 2}$ increases to 0.29 , the 2 nd stand becomes more unstable than 1st stand. There exists an optimal value of $h_{e, 2}$ for the multistand system which is related to the maximum critical velocity, as shown in Figure 11.

The overall critical velocity changing trend for the time delay system and nondelay system is the same. But the optimal values of $h_{e, 2}$ are different for the two systems, because the stability of the 2nd stand becomes worse when considering the time delay effect. The optimal values of $h_{e, 2}$ for the two systems are $0.33 \mathrm{~mm}$ and $0.28 \mathrm{~mm}$, respectively. Obviously, the optimal value of $h_{e, 2}$ for the delay system is more consistent with the actual production. It suggests that by redistributing the reduction of the tandem rolling mills, we can improve the stability of the tandem rolling mills.

The critical velocity of a single stand changing along with the increase of the reduction is not linear. When the reduction is small, the critical velocity of the stand is very sensitive to the reduction changing. But as the reduction goes up, the decrease of critical velocity slows down. So, as shown in Figure 15 , when $h_{e, 2}$ is bigger than a certain point, the critical velocities of the two systems both go down slowly.

It has to be clarified that the optimal $h_{e, 2}$ value for the twostand system may not work for five stand system. There exist four delay times in five-stand tandem rolling mills, which makes the relationship between stands more complex.

\section{Conclusions}

In this paper, the effects of interstand tension variation and strip variation transportation between adjacent stands with time delay on tandem rolling mills were studied in detail through comparison of different models. Stability analysis shows that interstand tension couples adjacent stands together and has just a little effect on the critical velocity of the chatter model. The strip gauge variation passed on between stands reduces the critical velocity dramatically. However, the time delay effect has very limited effects on both the critical velocity and the frequency. But it does not mean that the time delay effect can be neglected when modeling the rolling system. By comparing the critical velocities of the delay and nondelay system, the influences of delay time as a single factor on multistand rolling system were studied. More detailed and quantitative explanation is put forward to the relationship of two adjacent stands. In the big picture, the critical velocity of the time delay system is just slightly smaller than the nondelay system. But the delay time worsens the stability of downstream stand and makes the relationship between consecutive stands more complex. The time delay effect changes the optimal process parameters values aimed at obtaining the maximum critical velocity. To get preferable rolling process parameter configuration for tandem rolling mills, time delay effect must be involved.

\section{Appendix}

Consider

$$
\begin{aligned}
& d F=F_{1} d h_{d}+F_{2} d \dot{h}_{d}+F_{3} d \sigma_{e}+F_{4} d \sigma_{d}+F_{5} d h_{e}, \\
& F_{1}=\left(\frac{\partial F}{\partial h_{d}}\right)_{s} \\
& =\int_{x_{d}}^{x_{n}}\left(\frac{\partial p_{d}}{\partial h_{d}}\right)_{s} d x+\int_{x_{n}}^{x_{e}}\left(\frac{\partial p_{e}}{\partial h_{d}}\right)_{s} d x \\
& +\left(k_{f e}-\sigma_{e}\right)\left(\frac{\partial x_{e}}{\partial h_{d}}\right)_{s}, \\
& F_{2}=\left(\frac{\partial F}{\partial \dot{h}_{d}}\right)_{s} \\
& =\int_{x_{d}}^{x_{n}}\left(\frac{\partial p_{d}}{\partial \dot{h}_{d}}\right)_{s} d x-\left(k_{f d}-\sigma_{d}\right)\left(\frac{\partial x_{d}}{\partial \dot{h}_{d}}\right)_{s}, \\
& F_{3}=\left(\frac{\partial F}{\partial \sigma_{e}}\right)_{s}=\int_{x_{n}}^{x_{e}}\left(\frac{\partial p_{e}}{\partial \sigma_{e}}\right)_{s} d x \\
& F_{4}=\left(\frac{\partial F}{\partial \sigma_{d}}\right)_{s}=\int_{x_{d}}^{x_{n}}\left(\frac{\partial p_{d}}{\partial \sigma_{d}}\right)_{s} d x, \\
& F_{5}=\left(\frac{\partial F}{\partial h_{e}}\right)_{s} \\
& =\int_{x_{n}}^{x_{e}}\left(\frac{\partial p_{e}}{\partial h_{e}}\right)_{s} d x+\left(k_{f e}-\sigma_{e}\right)\left(\frac{\partial x_{e}}{\partial h_{e}}\right)_{s}, \\
& d v_{e}=P_{1} d h_{d}+P_{2} d \dot{h}_{d}+P_{3} d \sigma_{e}+P_{4} d \sigma_{d}+P_{5} d h_{e}, \\
& P_{1}=\left(\frac{\partial v_{e}}{\partial h_{d}}\right)_{s}=\frac{v_{r}}{h_{e}}+\frac{2 v_{r} x_{n}}{h_{e} R}\left(\frac{\partial x_{n}}{\partial h_{d}}\right)_{s}, \\
& P_{2}=\left(\frac{\partial v_{e}}{\partial \dot{h}_{d}}\right)_{s}=\frac{x_{e}-x_{n}}{h_{e}}+\frac{2 v_{r} x_{n}}{h_{e} R}\left(\frac{\partial x_{n}}{\partial \dot{h}_{d}}\right)_{s}, \\
& P_{3}=\left(\frac{\partial v_{e}}{\partial \sigma_{e}}\right)_{s}=\frac{2 v_{r} x_{n}}{h_{e} R}\left(\frac{\partial x_{n}}{\partial \sigma_{e}}\right)_{s}, \\
& P_{4}=\left(\frac{\partial v_{e}}{\partial \sigma_{d}}\right)_{s}=\frac{2 v_{r} x_{n}}{h_{e} R}\left(\frac{\partial x_{n}}{\partial \sigma_{d}}\right)_{s}, \\
& P_{5}=\left(\frac{\partial v_{e}}{\partial h_{e}}\right)_{s}=-\frac{v_{r} h_{n}}{h_{e}{ }^{2}}+\frac{2 v_{r} x_{n}}{h_{e} R}\left(\frac{\partial x_{n}}{\partial h_{e}}\right)_{s},
\end{aligned}
$$




$$
\begin{aligned}
d v_{d} & =Q_{1} d h_{d}+Q_{2} d \dot{h}_{d}+Q_{3} d \sigma_{e}+Q_{4} d \sigma_{d}+Q_{5} d h_{e}, \\
Q_{1} & =\left(\frac{\partial v_{d}}{\partial h_{d}}\right)_{s}=-\frac{v_{e} h_{e}}{h_{d}^{2}}+\frac{h_{e}}{h_{d}}\left(\frac{\partial v_{e}}{\partial h_{d}}\right)_{s}, \\
Q_{2} & =\left(\frac{\partial v_{d}}{\partial h_{d}}\right)_{s}=\frac{-x_{e}}{h_{d}}+\frac{h_{e}}{h_{d}}\left(\frac{\partial v_{e}}{\partial \dot{h}_{d}}\right)_{s}, \\
Q_{3} & =\left(\frac{\partial v_{d}}{\partial \sigma_{e}}\right)_{s}=\frac{h_{e}}{h_{d}}\left(\frac{\partial v_{e}}{\partial \sigma_{e}}\right)_{s} \\
Q_{4} & =\left(\frac{\partial v_{d}}{\partial \sigma_{d}}\right)_{s}=\frac{h_{e}}{h_{d}}\left(\frac{\partial v_{e}}{\partial \sigma_{d}}\right)_{s} \\
Q_{5} & =\left(\frac{\partial v_{d}}{\partial h_{e}}\right)_{s}=\frac{v_{e}}{h_{d}}+\frac{h_{e}}{h_{d}}\left(\frac{\partial v_{e}}{\partial h_{e}}\right)_{s} .
\end{aligned}
$$

The intermedia variables are given as follows:

$$
\begin{aligned}
& \left(\frac{\partial x_{n}}{\partial h_{d}}\right)_{s}=\left(-\frac{g 1}{8 u}+\frac{1}{4 u}-\frac{x_{e}}{4 h_{e}}\right) \sec (g)^{2}+\sqrt{\frac{R}{4 h_{d}}} \\
& \cdot \tan (g)+\left(\frac{\partial x_{n}}{\partial x_{e}}\right)_{s}\left(\frac{\partial x_{e}}{\partial h_{d}}\right)_{s}+\left(\frac{\partial x_{n}}{\partial k_{f d}}\right)_{s} \\
& \cdot\left(\frac{\partial k_{f d}}{\partial h_{d}}\right)_{s} \\
& g 1=\log \left(\frac{h_{e} k_{f e}}{h_{d} k_{f d}} \frac{k_{f d}-\sigma_{d}}{k_{f e}-\sigma_{e}}\right), \\
& g=\frac{1}{4} \sqrt{\frac{h_{d}}{R}}\left(2 \sqrt{\frac{R}{h_{d}}} \tan ^{-1}\left(\frac{x_{e}}{\sqrt{R h_{d}}}\right)\right. \\
& \left.+2 \sqrt{\frac{R}{h_{d}}} \tan ^{-1}\left(\frac{x_{d}}{\sqrt{R h_{d}}}\right)-\frac{g 1}{u}\right), \\
& \left(\frac{\partial x_{n}}{\partial x_{e}}\right)_{s}=\frac{h_{d} \sec (g)^{2}}{2 h_{e}} \\
& \left(\frac{\partial x_{n}}{\partial k_{f d}}\right)_{s}=\frac{h_{d}}{4 u}\left(\frac{1}{k_{f d}}-\frac{1}{k_{f d}-\sigma_{d}}\right) \sec (g)^{2}, \\
& \left(\frac{\partial k_{f d}}{\partial h_{d}}\right)=-\frac{n \sigma_{0}}{h_{d}}\left(A+\log \left(\frac{h_{0}}{h_{d}}\right)\right)^{n-1}, \\
& \left(\frac{\partial x_{n}}{\partial \dot{h}_{d}}\right)_{s}=\frac{1}{2} \sec (g)^{2}\left(\frac{\partial x_{d}}{\partial \dot{h}_{d}}\right)_{s}, \\
& \left(\frac{\partial x_{n}}{\partial \sigma_{e}}\right)_{s}=-\frac{h_{d} \sec (g)^{2}}{4 u\left(k_{f e}-\sigma_{e}\right)}, \\
& \left(\frac{\partial x_{n}}{\partial \sigma_{d}}\right)_{s}=\frac{h_{d} \sec (g)^{2}}{4 u\left(k_{f d}-\sigma_{d}\right)},
\end{aligned}
$$$$
\left(\frac{\partial x_{n}}{\partial h_{e}}\right)_{s}=-\frac{h_{d} \sec (g)^{2}}{4 u h_{e}}+\left(\frac{\partial x_{n}}{\partial x_{e}}\right)_{s}\left(\frac{\partial x_{e}}{\partial h_{e}}\right)_{s}
$$$$
+\left(\frac{\partial x_{n}}{\partial k_{f e}}\right)_{s}\left(\frac{\partial k_{f e}}{\partial h_{e}}\right)_{s}
$$$$
\left(\frac{\partial x_{n}}{\partial k_{f e}}\right)_{s}=\frac{h_{d}}{4 u}\left(\frac{1}{k_{f e}-\sigma_{e}}-\frac{1}{k_{f e}}\right) \sec (g)^{2},
$$$$
\left(\frac{\partial k_{f e}}{\partial h_{e}}\right)_{s}=-\frac{n \sigma_{0}}{h_{e}}\left(A+\log \left(\frac{h_{0}}{h_{e}}\right)\right)^{n-1},
$$$$
\left(\frac{\partial x_{e}}{\partial h_{d}}\right)_{s}=-\sqrt{\frac{R}{4\left(h_{e}-h_{d}\right)}},
$$$$
\left(\frac{\partial x_{e}}{\partial h_{e}}\right)_{s}=\sqrt{\frac{R}{4\left(h_{e}-h_{d}\right)}}
$$$$
\left(\frac{\partial x_{d}}{\partial \dot{h}_{d}}\right)_{s}=\frac{R h_{d}}{2 v_{r} h_{n}}
$$$$
\left(\frac{\partial p_{e}}{\partial h_{d}}\right)_{s}=\left(\frac{\partial p_{e}}{\partial h}\right)_{s}+\left(\frac{\partial p_{e}}{\partial k_{f}}\right)_{s}\left(\frac{\partial k_{f}}{\partial h_{d}}\right)_{s}+\left(\frac{\partial p_{e}}{\partial H_{e}}\right)_{s}
$$$$
\cdot\left(\frac{\partial H_{e}}{\partial h_{d}}\right)_{s}+\left(\frac{\partial p_{e}}{\partial H}\right)_{s}\left(\frac{\partial H}{\partial h_{d}}\right)_{s},
$$$$
\left(\frac{\partial p_{e}}{\partial h}\right)_{s}=\frac{\left(k_{f e}-\sigma_{e}\right) k_{f} e^{u\left(H_{e}-H\right)}}{h_{e} k_{f e}},
$$$$
\left(\frac{\partial p_{e}}{\partial k_{f}}\right)_{s}=\frac{\left(k_{f e}-\sigma_{e}\right) h e^{u\left(H_{e}-H\right)}}{h_{e} k_{f e}},
$$$$
\left(\frac{\partial k_{f}}{\partial h_{d}}\right)_{s}=-\frac{\sigma_{0} n}{h}\left(A+\ln \left(\frac{h_{0}}{h}\right)\right)^{n-1},
$$$$
\left(\frac{\partial p_{e}}{\partial H_{e}}\right)_{s}=\frac{\left(k_{f e}-\sigma_{e}\right) h k_{f} u e^{u\left(H_{e}-H\right)}}{h_{e} k_{f e}}
$$$$
\left(\frac{\partial H_{e}}{\partial h_{d}}\right)_{s}=-\frac{R \arctan \left(x_{e} / \sqrt{R h_{d}}\right)}{h_{d}^{2} \sqrt{R / h_{d}}}-\frac{x_{e}}{h_{d} h_{e}}
$$$$
+\left(\frac{\partial H_{e}}{\partial x_{e}}\right)_{s}\left(\frac{\partial x_{e}}{\partial h_{d}}\right)_{s}
$$$$
\left(\frac{\partial p_{e}}{\partial H}\right)_{s}=-\frac{\left(k_{f e}-\sigma_{e}\right) h k_{f} u e^{u\left(H_{e}-H\right)}}{h_{e} k_{f e}},
$$$$
\left(\frac{\partial H}{\partial h_{d}}\right)_{s}=-\frac{R \arctan \left(x / \sqrt{R h_{d}}\right)}{h_{d}^{2} \sqrt{R / h_{d}}}-\frac{x}{h_{d} h},
$$$$
\left(\frac{\partial p_{e}}{\partial \sigma_{e}}\right)_{s}=-\frac{h k_{f} e^{u\left(H_{e}-H\right)}}{h_{e} k_{f e}},
$$ 


$$
\begin{aligned}
& \left(\frac{\partial p_{\mathrm{e}}}{\partial h_{\mathrm{e}}}\right)_{s}=\left(\frac{\partial p_{\mathrm{e}}}{\partial k_{f e}}\right)_{s}\left(\frac{\partial k_{f e}}{\partial h_{e}}\right)_{s}+\left(\frac{\partial p_{\mathrm{e}}}{\partial H_{e}}\right)_{s}\left(\frac{\partial H_{e}}{\partial x_{e}}\right)_{s} \\
& \cdot\left(\frac{\partial x_{e}}{\partial h_{e}}\right)_{s}-\frac{\left(k_{f e}-\sigma_{e}\right) h k_{f} e^{u\left(H_{e}-H\right)}}{h_{e}^{2} k_{f e}} \\
& \left(\frac{\partial p_{e}}{\partial k_{f e}}\right)_{s}=\frac{h k_{f} e^{u\left(H_{e}-H\right)}}{h_{e} k_{f e}}-\frac{\left(k_{f} e-\sigma_{e}\right) h k_{f} e^{u\left(H_{e}-H\right)}}{h_{e} k_{f e}^{2}}, \\
& \left(\frac{\partial H_{e}}{\partial x_{e}}\right)_{s}=\frac{2}{h_{e}} \\
& \left(\frac{\partial p_{\mathrm{d}}}{\partial h_{d}}\right)_{s}=\left(\frac{\partial p_{d}}{\partial k_{f d}}\right)_{s}\left(\frac{\partial k_{f d}}{\partial h_{d}}\right)_{s}+\left(\frac{\partial p_{d}}{\partial h}\right)_{s} \\
& +\left(\frac{\partial p_{d}}{\partial k_{f}}\right)_{s}\left(\frac{\partial k_{f}}{\partial h_{d}}\right)_{s}+\left(\frac{\partial p_{d}}{\partial H}\right)_{s}\left(\frac{\partial H}{\partial h_{d}}\right)_{s} \\
& -\frac{\left(k_{f d}-\sigma_{d}\right) h k_{f} e^{u\left(H-H_{d}\right)}}{h_{d}^{2} k_{f d}} \\
& \left(\frac{\partial p_{d}}{\partial k_{f d}}\right)_{s}=\frac{h k_{f} e^{u\left(H-H_{d}\right)}}{h_{d} k_{f d}} \\
& -\frac{\left(k_{f d}-\sigma_{d}\right) h k_{f} e^{u\left(H-H_{d}\right)}}{h_{d} k_{f d}^{2}}, \\
& \left(\frac{\partial p_{d}}{\partial h}\right)_{s}=\frac{\left(k_{f d}-\sigma_{d}\right) k_{f} e^{u\left(H-H_{d}\right)}}{h_{d} k_{f d}}, \\
& \left(\frac{\partial p_{d}}{\partial k_{f}}\right)_{s}=\frac{\left(k_{f d}-\sigma_{d}\right) h e^{u\left(H-H_{d}\right)}}{h_{d} k_{f d}}, \\
& \left(\frac{\partial p_{d}}{\partial H_{d}}\right)_{s}=-\frac{\left(k_{f d}-\sigma_{d}\right) h k_{f} u e^{u\left(H-H_{d}\right)}}{h_{d} k_{f d}}, \\
& \left(\frac{\partial p_{d}}{\partial H}\right)_{s}=\frac{\left(k_{f d}-\sigma_{d}\right) h k_{f} u e^{u\left(H-H_{d}\right)}}{h_{d} k_{f d}} \\
& \left(\frac{\partial p_{d}}{\partial \dot{h}_{d}}\right)_{s}=\left(\frac{\partial p_{d}}{\partial H_{d}}\right)_{s}\left(\frac{\partial H_{d}}{\partial x_{d}}\right)_{s}\left(\frac{\partial x_{d}}{\partial \dot{h}_{d}}\right)_{s}, \\
& \left(\frac{\partial H_{d}}{\partial x_{d}}\right)_{s}=\frac{2}{h_{d}}, \\
& \left(\frac{\partial p_{d}}{\partial \sigma_{d}}\right)_{s}=-\frac{h k_{f} e^{u\left(H-H_{d}\right)}}{h_{d} k_{f d}} \\
& H_{e}=2 \sqrt{\frac{R}{h_{d}}} \tan ^{-1}\left(\frac{x_{e}}{\sqrt{R h_{d}}}\right) \text {, }
\end{aligned}
$$$$
H_{d}=2 \sqrt{\frac{R}{h_{d}}} \tan ^{-1}\left(\frac{x_{d}}{\sqrt{R h_{d}}}\right) \text {, }
$$

\section{Conflict of Interests}

The authors declare that there is no conflict of interests regarding the publication of this paper.

\section{Acknowledgments}

The authors gratefully acknowledge the support of the National Natural Science Foundation of China no. 51175035, Ph.D. Programs Foundation of Ministry of Education of China no. 20100006110024, the Fundamental Research Funds for the Central Universities no. FRF-BR-14-006A, and Beijing Higher Education Young Elite Teacher Project no. YETP0367.

\section{References}

[1] I. S. Yun, W. R. D. Wilson, and K. F. Ehmann, "Review of chatter studies in cold rolling," International Journal of Machine Tools and Manufacture, vol. 38, no. 12, pp. 1499-1530, 1998.

[2] J. X. Zhou, Tandem Mill Vibration Control, Metallurgical Industry Press, Beijing, China, 1st edition, 1998.

[3] G. Zhiying, Z. Yong, and Z. Lingqiang, "Review of modelling and theoretical studies on chatter in the rolling mills," Journal of Mechanical Engineering, vol. 51, no. 16, pp. 87-105, 2015.

[4] H. Zhao and K. F. Ehmann, "Stability analysis of chatter in tandem rolling mills-part 2: the regenerative effect," Journal of Manufacturing Science and Engineering-Transactions of the ASME, vol. 135, no. 3, Article ID 031002, 11 pages, 2013.

[5] P.-H. Hu and K. F. Ehmann, "Regenerative effect in rolling chatter," Journal of Manufacturing Processes, vol. 3, no. 2, pp. 8293, 2001.

[6] P. H. Hu, Stability and Chatter in Rolling, Northwestern University, Evanston, Ill, USA, 1998.

[7] H. Y. Zhao and K. F. Ehmann, "Stability analysis of chatter in tandem rolling mills-part 1: single- and multi-stand negative damping effect," Journal of Manufacturing Science and Engineering, vol. 135, no. 3, Article ID 031001, 2013.

[8] Y. Kimura, Y. Sodani, N. Nishiura et al., "Analysis of chaffer in tandem cold rolling mills," ISIJ International, vol. 43, no. 1, pp. 77-84, 2003.

[9] M. R. Niroomand, R. M. Forouzan, and M. Salimi, "Theoretical and experimental analysis of chatter in tandem cold rolling mills based on wave propagation theory," ISIJ International, vol. 55, no. 3, pp. 637-646, 2015.

[10] A. Heidari, M. R. Forouzan, and S. Akbarzadeh, "Development of a rolling chatter model considering unsteady lubrication," ISIJ International, vol. 54, no. 1, pp. 165-170, 2014.

[11] A. Heidari and M. R. Forouzan, "Optimization of cold rolling process parameters in order to increasing rolling speed limited by chatter vibrations," Journal of Advanced Research, vol. 4, no. 1, pp. 27-34, 2013. 
[12] B. BahramiNejad, M. Dehghani, and S. A. Mousavi, "Simulation of two stands cold rolling mill process using neural networks and genetic algorithms in combination to avoid the chatter phenomenon," Majlesi Journal of Electrical Engineering, vol. 9, no. 1, pp. 21-24, 2014.

[13] X. X. Liao, Theory Methods and Application of Stability, Huazhong Science and Engineering University Press, Wuhan, China, 1999.

[14] V. B. Kolmanovskii and V. R. Nosov, Stability of Functional Differential Equations, Academic Press, New York, NY, USA, 1986. 


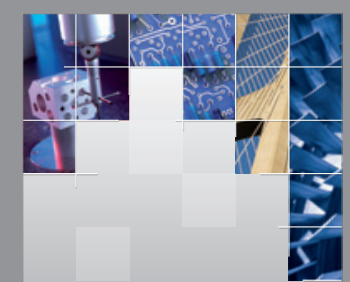

\section{Enfincering}
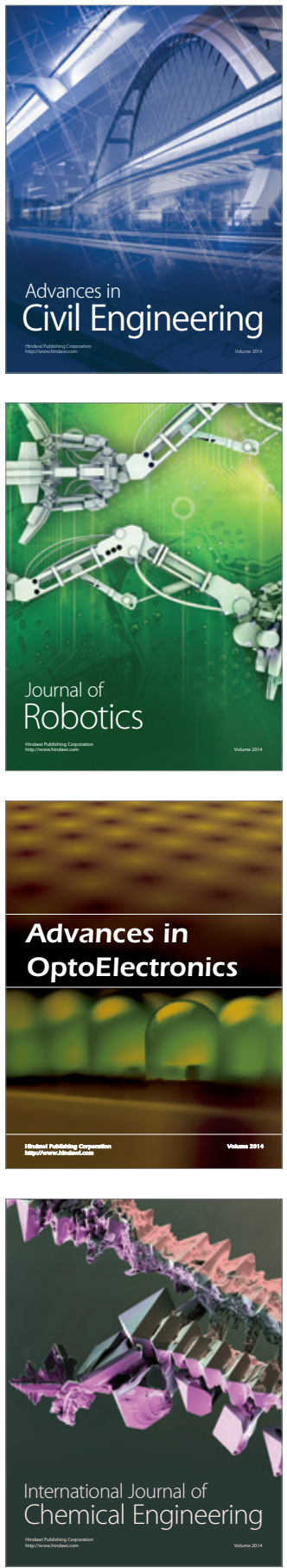

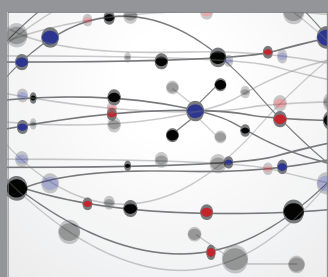

The Scientific World Journal

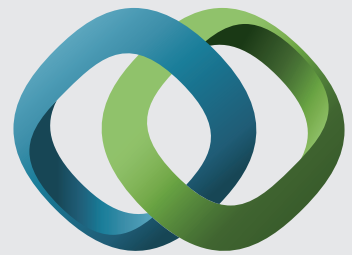

\section{Hindawi}

Submit your manuscripts at

http://www.hindawi.com
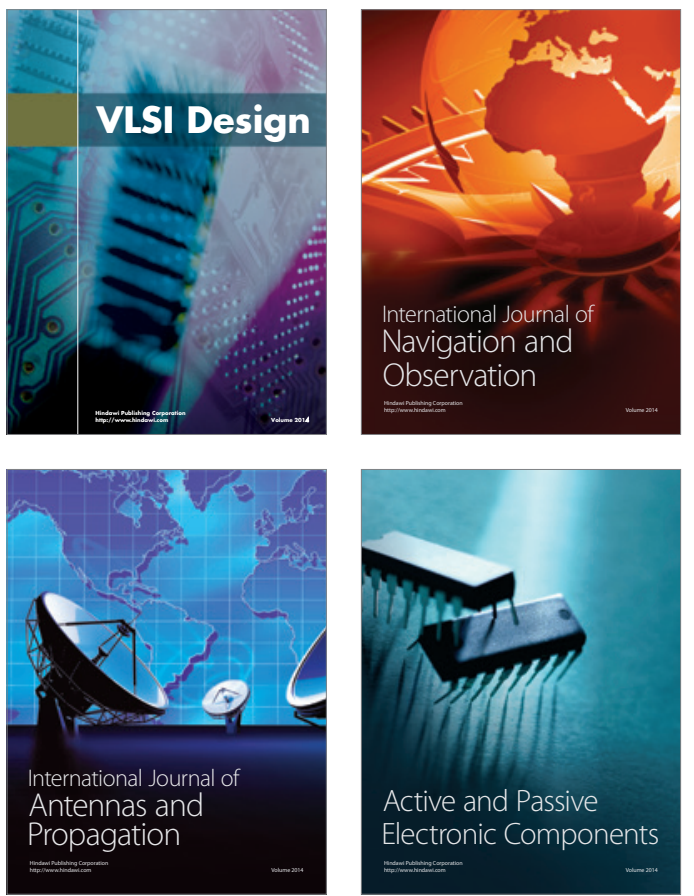
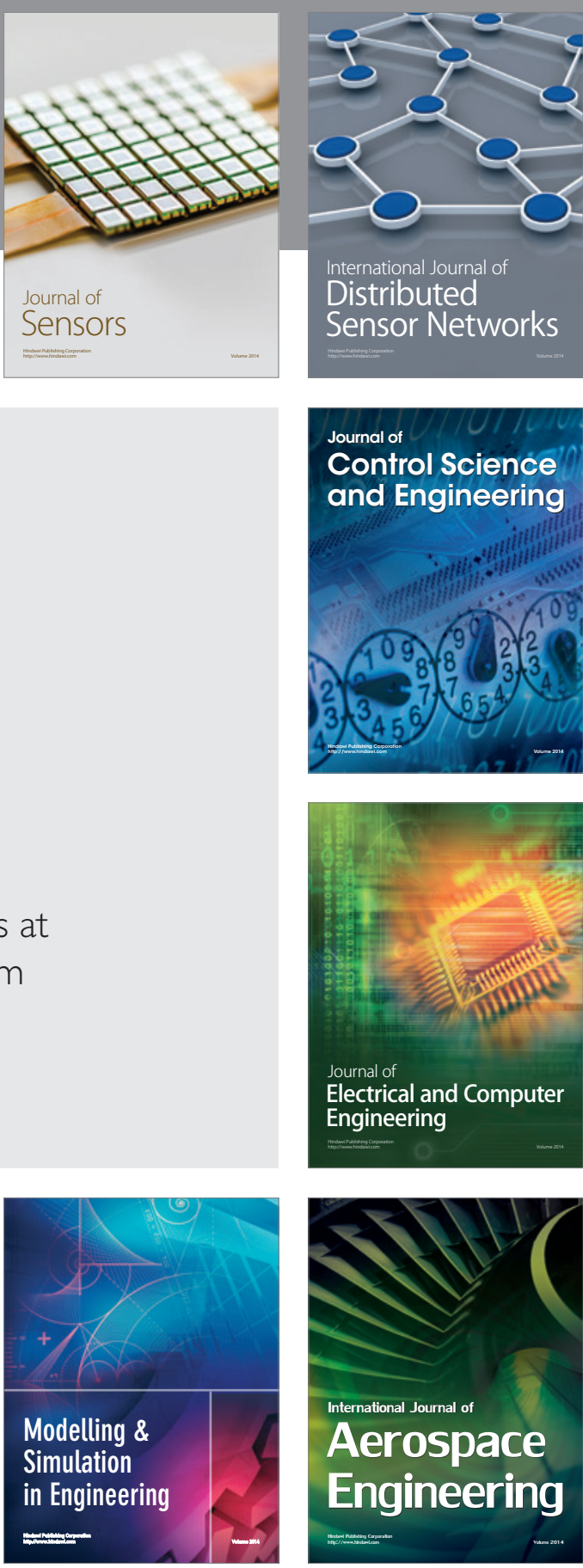

International Journal of

Distributed

Sensor Networks

Journal of

Control Science

and Engineering
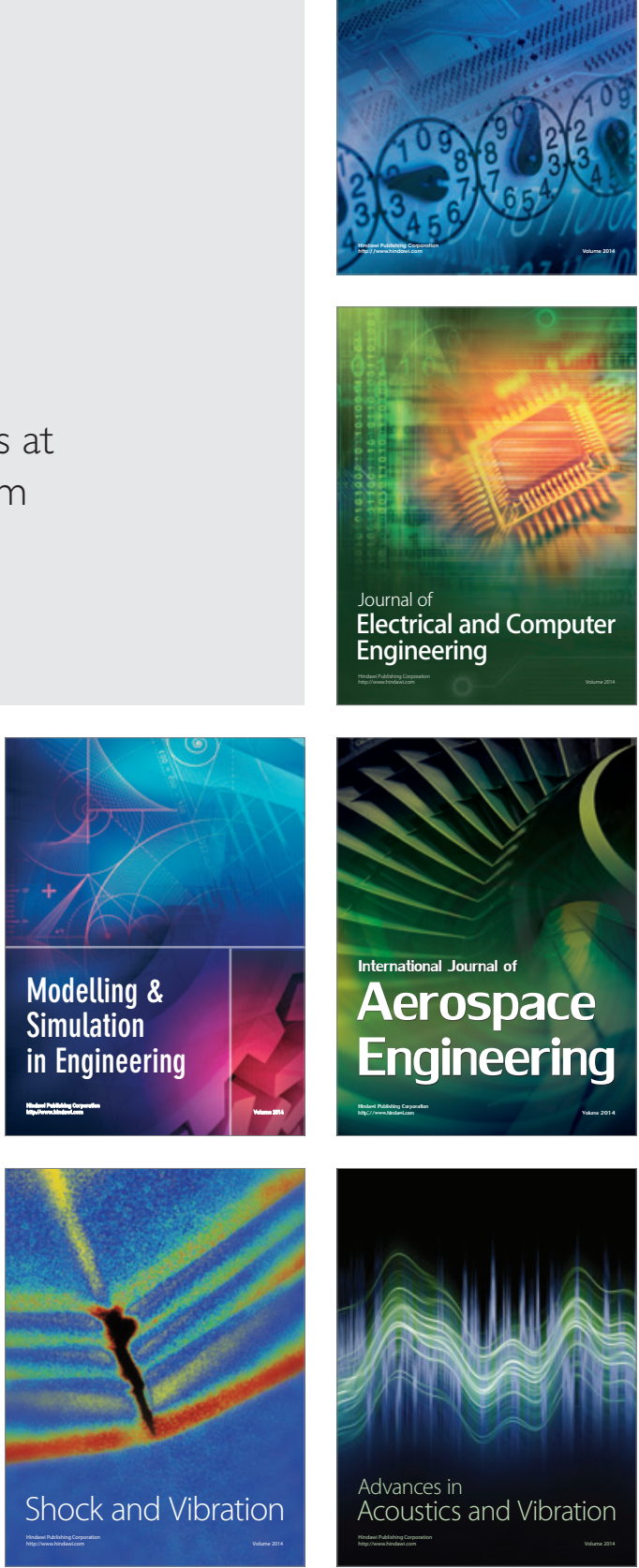